NOTICE: this is the author's version of a work that was accepted for publication in Advances in Water Resources. Changes resulting from the publishing process, such as peer review, editing, corrections, structural formatting, and other quality control mechanisms may not be reflected in this document. Changes may have been made to this work since it was submitted for publication. A definitive version was subsequently published in Advances in Water Resources, Vol. 74 (2014). DOI: 10.1016/j.advwatres.2014.07.012 


\title{
Characterization of Ethiopian mega hydrogeological regimes using GRACE, TRMM and GLDAS Datasets
}

\author{
J.L. Awange ${ }^{\mathrm{a}}$, M. Gebremichael ${ }^{\mathrm{b}}$, E. Forootan $^{\mathrm{c}}$, G. Wakbulcho ${ }^{\mathrm{d}, \mathrm{g}}$, R. Anyah ${ }^{\mathrm{e}}$, \\ V.G. Ferreira ${ }^{\mathrm{f}}$, T. Alemayehu ${ }^{\mathrm{b}}$ \\ ${ }^{a}$ Western Australian Centre for Geodesy and The Institute for Geoscience Research, Curtin \\ University, Perth, Australia \\ ${ }^{b}$ Civil and Environmental Engineering Department, University of California, Los Angeles, \\ $U S A$ \\ ${ }^{c}$ Institute of Geodesy and Geoinformation (IGG), Bonn University, Bonn, Germany \\ ${ }^{d}$ Ethiopian Institute of Water Resources, Addis Ababa University, Ethiopia \\ ${ }^{e}$ Department of Natural Resources and the Environment, University of Connecticut, USA

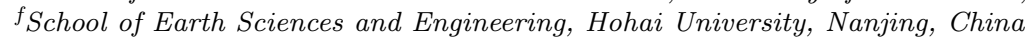 \\ ${ }^{g}$ Department of Hydraulic and Water Resources Engineering, Arba Minch University, Arba \\ Minch, Ethiopia
}

\begin{abstract}
Understanding the spatio-temporal characteristics of water storage changes is crucial for Ethiopia, a country that is facing a range of challenges in water management caused by anthropogenic impacts as well as climate variability. In addition to this, the scarcity of in-situ measurements of soil moisture and groundwater, combined with intrinsic "scale limitations" of traditional methods used in hydrological characterization are further limiting the ability to assess water resource distribution in the region. The primary objective of this study is therefore to apply remotely sensed and model data over Ethiopia in order to (i) test the performance of models and remotely sensed data in modeling water resources distribution in un-gauged arid regions of Ethiopia, (ii) analyze the inter-annual and seasonal variability as well as changes in total water storage (TWS) over Ethiopia, (iii) understand the relationship between TWS changes, rainfall, and soil moisture anomalies over the study region, and (iv) identify the relationship between the characteristics of aquifers and TWS changes. The data used in this study includes; monthly gravity field data from the Grav-
\end{abstract}

Email address: J.Awange@curtin.edu.au (J.L. Awange)

Preprint submitted to Advances in Water Resources

August 4, 2014 
ity Recovery And Climate Experiment (GRACE) mission, rainfall data from the Tropical Rainfall Measuring Mission (TRMM), and soil moisture from the Global Land Data Assimilation System (GLDAS) model. Our investigation covers a period of 8 years from 2003 to 2011. The results of the study show that the western part and the north-eastern lowlands of Ethiopia experienced decrease in TWS water between 2003-2011, whereas all the other regions gained water during the study period. The impact of rainfall seasonality was also seen in the TWS changes. Applying the statistical method of Principal Component Analysis (PCA) on TWS, soil moisture and rainfall variations showed the dominant annual water variability in the western, north-western, northern, and central regions, and the dominant seasonal variability in the western, north-western, and the eastern regions. A correlation analysis between TWS and rainfall indicate a minimum time lag of zero to a maximum of six months, whereas no lag is noticeable between soil moisture anomalies and TWS changes. The delay response and correlation coefficient between rainfall and TWS appears to be related to recharge mechanisms, revealing that most regions of Ethiopia receive indirect recharge. Our results also show that the TWS changes are higher in the western region and lower in the north-eastern region, and that the elevation influences soil moisture as well as TWS.

Keywords: TWS changes, Ethiopia, GRACE, TRMM, GLDAS, Hydrology, Climate

\section{Introduction}

Ethiopia's hydrology plays a significant international role, being the headwaters of the Blue Nile basin, where it contributes about $86 \%$ of the total annual flow of the Nile (Melesse, 2011; Sutcliffe \& Parks, 1999) and also approximately 90\% of inflow into Lake Turkana (Ferguson \& Harbott, 1982), a lake situated in the arid area of northern Kenya. In recent decades, however, extreme hydrological variability, seasonality, and anthropogenic factors are posing challenges to

8 the region's water resource management. For example, due to the large and in- 
creasing population pressure, insufficient agricultural production, a low number of developed energy sources, and drought episodes, Ethiopia, which has almost $94 \%$ of its population depending on wood fuel, is planning major hydropower and irrigation development schemes(Tesfagiorgis et al., 2011; Berhane et al., 2013). In addition to irrigation and hydroelectric dams, land degradation and changes in land cover in Ethiopia where forests are being converted to agricultural land are having impact on the Nile flow (see, e.g., Senay et al., 2009; Rientjes et al., 2011).

Characterizing water-storage in all its forms (surface, soil moisture, and groundwater) and their responses to the incoming (precipitation) and outgoing (evaporation and discharge) water masses, therefore, is of great importance in terms of understanding extreme changes in stored water triggered by natural and anthropogenic factors. This is of interest especially in areas where the seasonality of rainfall is strong and the welfare of the society relies on the availability of water, such as in Ethiopia.

To quantify the stored water resource of a region, soil moisture and groundwater have been documented to play a significant role (e.g., Rodell et al., 2007; Rodell \& Famiglietti, 2001; Swenson et al., 2008). For developing countries such as Ethiopia, however, in-situ networks of soil moisture and groundwater measurements are sparse. Therefore, these components are among the most difficult water budget parameters to obtain. To circumvent this shortfall, characterizing the hydrogeological regimes has been undertaken by considering their hydrogeological environments (see, e.g., Ayenew et al., 2008; Furi et al., 2012; Kebede et al., 2005, 2008; Yitbarek et al., 2012). Most of the previous studies have concentrated on the climatic characteristics (e.g., Conway \& Schipper, 2011; Seleshi \& Camberlin, 2006; Seleshi \& Zanke, 2004; Omondi et al., 2012, 2013, 2014; Shang et al., 2011; Taye \& Willems, 2012) and the use of environmental isotopes and hydrochemicals (e.g., Berhane et al., 2013) to trace the water availability in Ethiopia. For example, Berhane et al. (2013) found the environmental isotopes and hydrochemicals approach to be the most effective tool for differentiating various forms of geochemical reaction, and to infer the environmental 
factors affecting groundwater quality and its flow in the region.

Besides concentrating on climatic characteristics, most of the studies above are also restricted to small scale hydrological characterizations, which do not reflect the large-scale water storage variability over Ethiopia. Moreover, isotopes and hydrochemical-based methods are costly, require skilled experts, and are often difficult to apply over large areas, which are not easy to venture into, particularly in developing countries such as Ethiopia. Furthermore, most of the hydrological studies over Ethiopia focused only on regional characterizations. Generalizing such local outputs to the whole of Ethiopia is extremely difficult due to its vast range of climatic and topographic conditions.

Total water-storage (TWS), which is defined as the sum of all forms of water stored above and underneath the Earth's surface, is a key component of the terrestrial and global hydrological cycles that exerts important control over water, energy and biogeochemical fluxes, and thus plays a major role in the Earth's climate system (Rodell et al., 2004; Syed et al., 2008; Tapley et al., 2004). The Gravity Recovery And Climate Experiment (GRACE) mission offers the possibility of remotely sensing global and regional TWS changes. Launched in 2002 as a joint project of the US and Germany, GRACE products have contributed enormously to the study of changes in total water storage.

With the help of complementary data sets, GRACE-derived products offer the possibility of monitoring groundwater depletion in data poor regions of the world (Famiglietti \& Rodell, 2013; Forootan et al., 2014; Rodell et al., 2007). To date, however, except for studies that have been done at continental or global scales (Reager \& Famiglietti, 2009; Schmidt et al., 2008) and those in connection with the Nile Basin (Bonsor et al., 2010; Melesse et al., 2010; Awange et al., 2008; Awange, 2012; Awange et al., 2013a; Awange \& Kyalo Kiema, 2013; Awange et al., 2013b, 2014) GRACE satellite products have not been applied specifically to the whole Ethiopian basins at a local level. Within Ethiopia, for example, the application of GRACE products are reported e.g., in Bonsor et al. (2010) and Melesse et al. (2010) with respect to the study of the Blue Nile. For instance, Melesse et al. (2010) presents the low and high flow characteristics of the Blue 
Nile River using wavelets and applies GRACE products to analyse moisture flux.

One of the major challenges in applying the GRACE products to estimate TWS changes over Ethiopian basins is the fact that only 2 out of the 12 basins (Abbay and Wabishebele) can barely fulfill the requirement for the smallest resolvable basin area of $200,000 \mathrm{~km}^{2}$ (see also Tapley et al., 2004). Furthermore, Longuevergne et al. (2010) have pointed out that an accurate estimate of TWS changes in small basins using GRACE-derived products requires a compromise between competing needs for noise suppression and spatial resolution. To overcome the spatial limitations, in the current study, Ethiopia was divided into ten regions of equal sizes of $4^{\circ} \times 4^{\circ}$. For each region, TWS were computed from GRACE data using the approaches presented in (Wahr et al., 1998).

This contribution focuses on the remotely-sensed TWS changes over Ethiopia using GRACE products. For the purpose of evaluating GRACE products, the study also uses rainfall and soil moisture data based on products from the Tropical Rainfall Measuring Mission (TRMM) (Kummerow et al., 1998) and the Global Land Data Assimilation System (GLDAS) (Rodell et al., 2004), respectively. The major aims of the current study are: i) understanding the response of Ethiopian aquifers to TWS changes from information obtained following the analysis of inter-annual (i.e., between years variability), and intra-annual (i.e., processes that occur on a time scale of less than one year, but more than one month) GRACE products, ii) depicting the reaction of each region to hydrological input (rainfall) including any time delays, and iii) identifying the dominant pattern of intra-annual, annual, and seasonal variability over Ethiopia by applying the statistical method of Principal Component Analysis (PCA) on GRACEderived TWS, soil moisture, and rainfall patterns. Knowledge of the lag time is important for understanding the longest period over which the available stored groundwater can be sustainably exploited after rainy seasons.

The remainder of this study is organized as follows; in section 2, the study area and its characteristics are discussed. Section 3 presents the data used and the employed analysis methods. The results are presented and discussed 
in sections 4 and 5, respectively, and finally, section 6 summarizes the major findings of this study.

\section{Study Area}

\subsection{Location}

Ethiopia, located between latitudes $3^{\circ} 15^{\prime} \mathrm{N}$ to $15^{\circ} \mathrm{N}$ and longitudes $33^{\circ} \mathrm{E}$ to $48^{\circ} \mathrm{E}$, is a landlocked country bounded by Eritrea (North), South Sudan (South West), Sudan (North West), Kenya (South), Somalia (East) and Djibouti (North East), with a surface area of $1,127,127 \mathrm{~km}^{2}$. Its altitude ranges from nearly 120 $\mathrm{m}$ below mean sea level in the Dallol depression to about $4620 \mathrm{~m}$ above mean sea level at Mount Ras Dashen. It contains three major physiographic regions that include the western highlands and associated lowlands, the eastern highlands and associated lowlands, and the rift valley in between them, running from north-east to south-west, separating the eastern and western highlands (Fig. 1). It is because of these physiographic influences on the drainage systems that Ethiopia is counted as the water tower of East Africa, with twelve major basins; eight of which are river basins, one is a lake basin, and the remaining three are dry basins with no or insignificant out flow (FAO, 2005).

Ethiopia contributes to three major drainage systems (Fig 1), the Mediterranean Sea drainage system (Abbay, Blue Nile, Baro-Akobo, Mereb and Tekeze), the Great East African Rift-Valley drainage system (Omo-Ghibe, Awash, RiftValley Lakes, Danakil and Aysha) and the Indian Ocean drainage system (GenaleDawa, Wabishebelle and Ogaden). The groundwater resources of Ethiopia and their distribution vary depending on their respective geological, structural, and climatic conditions. The near-surface geological pattern that mainly govern the hydrogeological characteristics of Ethiopia constitutes the region's oldest basement rocks (Precambrian basement) (18\%), Paleozoic and Mesozoic sedimentary rocks $(25 \%)$, Tertiary volcanic (40\%), and Quaternary sediments and volcanics $(17 \%)$ (Alemayehu, 2006). It should be pointed out that there are also large areas with Tertiary sediments occurring mainly in the rift valley. 


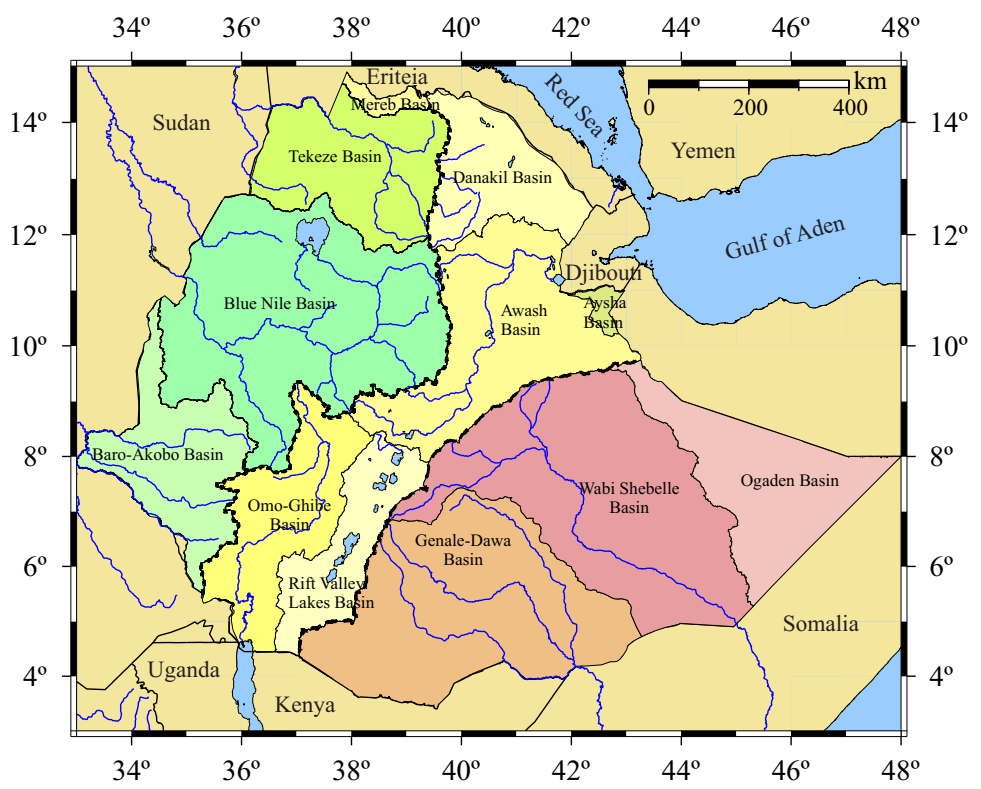

Figure 1: Major rivers and basins in Ethiopia. The black dashed line represents the major water divides between the Mediterranean Sea Basin (West), the Rift Valley endorheic basins (centre), and Indian Ocean Basin (East). Source: Modified from Nyssen et al. (2010). The different colours mark out the separate basins.

\subsection{Climate}

The climate of Ethiopia ranges from equatorial rainforest in the south and southwest, which is characterized by high rainfall and humidity; afro-alpine conditions on the summits of the Semien (western highlands) and Bale (eastern highlands) mountains, to the desert-like conditions of the Northeast, East and Southeast lowlands. The temperatures range from $60{ }^{\circ} \mathrm{C}$ at the Dallol depression, to freezing temperatures on the Mount Ras Dashen Plateau (MoWE, 2012). The mean annual rainfall varies from $3000 \mathrm{~mm}$ at Masha in the western highlands to barely $200 \mathrm{~mm}$ in the eastern lowlands (Engida \& Esteves, 2011; Romilly \& Gebremichael, 2011; Seleshi \& Zanke, 2004). Ethiopia experiences two rainfall seasons. The major rainy season (summer, regionally know as "Kiremt") extends from June to September, and accounts for nearly $60 \%$ (Segele et al., 2009), especially over the northern two thirds of the country. 
The minor rainy season (spring, regionally know as "Belg") usually begins in January/February and ends in April/May (Chukalla et al., 2013). In general rainfall over Ethiopia is influenced by both local scale forcing mechanisms associated with the Ethiopian Highlands as well as heterogeneous land surface characteristics. In addition, the rainfall variability is significantly influences by large (global) atmospheric circulation and sea surface temperatures. These large scale forcing mechanisms are normally expressed through El Nino Southern Oscillation (ENSO) induced anomalies, Quasi-Biennial Oscillation (QBO), as well as west-east sea surface temperature gradients over the equatorial Indian Ocean (e.g., Bewket \& Conway, 2007; Segeke et al., 2009). Table 1 shows the annual precipitation and potential evapotranspiration (ET) over the seven climatic zones over Ethiopia (Table 3 of Berhanu et al., 2013).

Table 1: Annual precipitation, average temperature, and potential evapotranspiration (ET) (Source: adapted from Berhanu et al. (2013)).

\begin{tabular}{lccc}
\hline Climatic zones & $\begin{array}{c}\text { Annual precipitation } \\
(\mathrm{mm})\end{array}$ & $\begin{array}{c}\text { Temperature } \\
\left({ }^{\circ} \mathrm{C}\right)\end{array}$ & $\begin{array}{c}\text { Annual ET } \\
(\mathrm{mm})\end{array}$ \\
\hline Arid & $<302$ & $>27.5$ & 2159 \\
Semi-arid & $302-350$ & $27.5-21$ & $1737-2159$ \\
Sub-moist & $350-566$ & $21-16$ & $1431-1737$ \\
Moist & $566-835$ & $16-11$ & $1124-1431$ \\
Sub-humid & $835-1189$ & $11-7.2$ & $895-1124$ \\
Humid & $1189-1711$ & $<7.5$ & $<895$ \\
Per-humid & $>1711$ & - & - \\
\hline
\end{tabular}

The common indicators of climate variability and changes are trends in precipitation and the maximum and minimum temperatures. Mengistu et al. (2013) reported a consistent warming trend in the maximum and minimum temperatures over the past few decades in Ethiopia. However, rainfall shows a declining trend for the east, south and southwest parts of Ethiopia (Seleshi \& Zanke, 2004). Additionally, for the central highlands, there is no evidence of trend in 
rainfall (Cheung et al., 2008). In general, there is no trend in the extremes of seasonal rainfall in Kiremt and Belg over Ethiopia (cf., Seleshi \& Camberlin, 2006). However, Marshall et al. (2012) have reported a gradual decline in evapotranspiration on the order of $5 \mathrm{~mm} /$ year over the coast of West Africa, the Sahel, and the western Ethiopian highlands, over a 31 years study period.

\section{Datasets and Methodology}

\subsection{Data}

(i) Gravity Recovery and Climate Experiment (GRACE) Data:

GRACE, a US/German satellite gravimetry mission that tracks changes in the Earth's gravity field (Tapley et al., 2004) has been the most commonly exploited satellite in the past decade for computing TWS. GRACE products have been used to quantify water storage changes at regional as well as global scales as reported for different regions (e.g., Awange et al., 2008; Forootan et al., 2012, 2014; Rodell et al., 2007). The GRACE Release-05 (RL05) Level-2 (L2) dataset provides the processed time-variable gravity field products applied in this study. The products are provided as sets of spherical harmonic coefficients (Stokes's coefficients) averaged over certain time periods (usually monthly). Spherical harmonic coefficients at high degrees are affected by correlated noise (Kusche, 2007; Kusche et al., 2009) that need to be smoothed before being used for the hydrological analysis in this study. These correlations can be reduced, using either an empirical method based on a polynomial fit (e.g. Swenson \& Wahr, 2006), or an a priori synthetic model of the observation geometry (e.g., Kusche, 2007). In this regard, the present study employed the DDK3 (Kusche et al., 2009) filtered monthly spherical harmonic coefficients dataset available from the official website of the International Centre for Global Earth Models (ICGEM) (http://icgem.gfz-potsdam.de/ICGEM/TimeSeries.html). The suitability of the employed DDK filter is discussed, e.g., in Werth et al. (2009). Our investigations covered the period from January 2003 to December 2011, and included 96 months of the German GeoForschungsZentrum (GFZ), Potsdam, 
products.

(ii) Global Land Data Assimilation System (GLDAS):

GLDAS model is developed jointly by the National Aeronautics and Space Administration (NASA), the National Oceanic and Atmospheric Administration (NOAA), and the National Centers for Environmental Prediction (NCEP) (Rodell et al., 2004). It drives multiple offline (not coupled to the atmosphere) land surface models that integrate huge quantities of observation-based data. GLDAS executes its outputs globally at a relatively high spatial and temporal resolution, enabled by the Land Information System (LIS) (Fang et al., 2009). The parameters in the GLDAS-monthly data fall into three main categories: water balance, energy balance, and forcing parameters. Water balance includes soil moisture parameters and other variables such as rainfall rate and surface runoff. To investigate the spatial and temporal variation of soil moisture over Ethiopia, we used the water balance monthly soil moisture data generated by NOAH LSM at a spatial resolution of $1^{\circ} \times 1^{\circ}$. The data was obtained freely from NASA, Goddard Earth Science Data and Information Services Center (GES DISC) (http://disc.sci.gsfc.nasa.gov/hydrology/data-holdings).

(iii) Tropical Rainfall Measuring Mission (TRMM) Satellite Rainfall: TRMM, a joint USA/Japan satellite mission, is designed to survey the rain structure, rate, and distribution in tropical and subtropical regions (latitude range $\pm 50^{\circ}$ ) (Kummerow et al., 1998). Amongst the TRMM precipitation products are those derived from integrated rainfall estimates from various sensors on-board satellites such as Precipitation Radar (PR), Special Sensor Microwave Imager (SSM/I)), infra-red (IR) data from geostationary satellites, and additional merged rain gauge observations (Liu et al., 2012; Huffman et al., 2007). TRMM-3B42 version version 7 (Huffman \& Bolvin, 2012), which was made available to the public on 22 May, 2012. It has a spatial resolution of $0.25^{\circ} \times 0.25^{\circ}$ and temporal resolution of 3 -hour. The major difference between the previous versions and the one used in this study is that the later has an 
improved scheme for weighting the incorporated rain-gauge data (Huffman \& Bolvin, 2012; Fleming \& Awange, 2013). The data was obtained from NASA GES DISC (http://mirador.gsfc.nasa.gov/).

Our motivation for selecting TRMM satellite data for this study is informed by the works of Dinku et al. (2007, 2008, 2010), and Beyene \& Meissner (2010) in terms of the validation of satellite products in the region, which includes nearly half of Ethiopia (i.e., the Blue Nile portion). In particular, Dinku et al. (2010) reported the fairly good performance of the TRMM-3B42 rainfall product compared to locally available rain gauge data. It should be pointed out that although another product, TRMM-3B43, provides monthly data, we used the shorter daily TRMM-3B42 product mainly due to the fact that these have been validated in the region (see, e.g., Dinku et al., 2010).

\subsection{Methods}

As already stated, GRACE products are limited in their usefulness to a spatial extent of greater than $200,000 \mathrm{~km}^{2}$. On the one hand, only two of the Ethiopian basins (Abbay and Wabishebele) can fulfill this criterion. On the other hand, Ethiopian catchments exhibit very different characteristics as they are climatically and environmentally extremely heterogeneous (see Section 2). In this respect, computing the TWS over Ethiopia as a whole might lead to wrong conclusions, since the basins' averages will follow the general variability of the area with the dominant signal. To overcome this problem, Ethiopia was subdivided into $4^{\circ}$ x $4^{\circ}$ (approximately $440 \mathrm{~km} \mathrm{x} 440 \mathrm{~km}$, i.e., $193,000 \mathrm{~km}^{2}$ ) blocks that enable (i) the spatial extent required for the valid consideration of the GRACE products, and (ii) minimizing the errors that might result from generalizing products for Ethiopia as a whole. This way, ten regions are obtained, whose minimum/maximum latitude and longitude, and designation to be used in this paper from now on are shown in Fig. 2. These subdivisions are made in such a way that larger physiographic regions of Ethiopia are represented as close as possible. Since GRACE data sets have already been smoothed using the DDK3 filter (Kusche et al., 2009), the computation of GRACE-derived TWS is 
undertaken following the approach presented in Wahr et al. (1998). For all 10 regions (Fig. 2), TWS values were generated with an approximate monthly temporal resolution over the study period (2003-2011), where the average field from the study period (2003-2011) was removed from the monthly TWS. The missing data from June 2003 was filled using a simple linear interpolation. The average error of the derived TWS over the whole region of the study was estimated to be less than $5 \mathrm{~mm}$ of water columns. This error was estimated using the formal errors of the Stokes coefficients smoothed using DDK3 filter and converted to TWS (cf. Wahr et al., 1998).

Monthly soil moisture down to $2 \mathrm{~m}$ beneath the surface has been computed from NOAA Land Surface Model (LSM) and water budget data obtained for four layers (0-10 cm, 10-40 cm, 40-100 cm and 100-200 cm), with spatial resolutions of $1^{\circ} \times 1^{\circ}$ and aggregated to a spatial domain of $4^{\circ} \times 4^{\circ}$. The average rainfall over each study region obtained from TRMM-3B42 was also rescaled to $4^{\circ} \times 4^{\circ}$ and a monthly temporal resolution. Since the TRMM 3B42-V7 rainfall rate are 3-hourly averages centered at the middle of each 3-hour period (i.e., 0 h, 3 h, 6 h, 9 h, 12 h, 15 h, 18 h, and 21 h), they are converted to total daily rainfall by first multiplying each 3-hourly rainfall rate by 3 to get the total rainfall for each 3-hour period, then added to obtain the desired monthly data, the sum of all the 3-hourly total rainfalls in within 24-hour period is multiplied by the number of the days for a specific month. Both TRMM and GLDAS data were filtered using a Gaussian filter of $300 \mathrm{~km}$ radius. The radius of $300 \mathrm{~km}$ was selected to be consistent with the smoothing impact of the DDK3 filter applied to the GRACE products. This value has been tested, e.g., in Werth et al. (2009) and was found to be applicable to nearly all river basins.

(i) Deriving Changes in Groundwater from GRACE and GLDAS:

The most important variables to use when deriving groundwater storage changes (GW) from GRACE-TWS data are; (i) changes in surface water storage (SWS) associated with lakes and reservoirs, (ii) changes in soil moisture (SM) and (iii) changes in snow water equivalent (SWE). However, when compared to the land surface, only about $0.7 \%$ of Ethiopia is covered by water bodies (MoWE, 


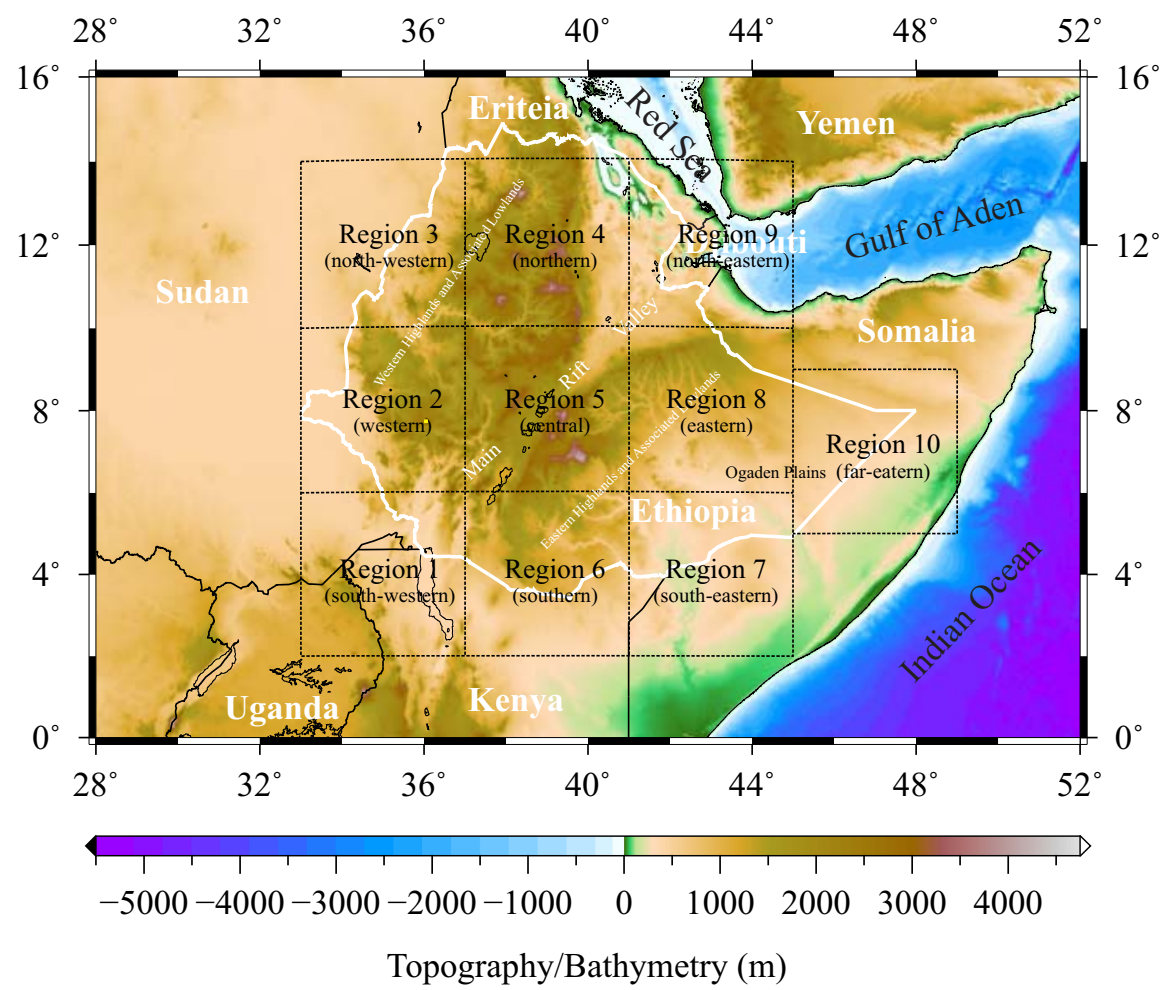

Figure 2: Ethiopia is divided into ten study regions of 4 degree by 4 degree to meet the spatial extent requirement of the GRACE products of $200,000 \mathrm{~km}^{2}$ and the physiographic regions.

2012). Therefore, we did not consider the contribution of surface water storage in computing TWS over Ethiopian regions since the areas of the existing water bodies and their fluctuations levels were quite small. The snow water equivalent was also not considered in our computation since its temporal variability over Ethiopia is negligible compared to the other contributors of TWS. Soil moisture anomalies were computed by removing the mean value over the extent of the study period (2003-2011) of the monthly soil moisture values. The monthly groundwater anomaly $(\Delta G W)$ was then obtained by subtracting changes in soil moisture from TWS changes as:

$$
G W=T W S-S M,
$$


assuming that the surface water and snow are insignificant. This approach has been previously applied by Rodell et al. (2009) in Northern India with the aim of estimating groundwater depletion.

In association with the GRACE-derived TWS estimates over the study region, Bonsor et al. (2010) used a recharge model for the Nile Basin, Zoomable Object Oriented Distributed Recharge Model (ZOODRM), to interpret the seasonal variation in TWS. They found that the simulated annual variation in groundwater storage and soil moisture accounts for $50-90 \%$ of the variations in the GRACE-derived TWS.

(ii) Total Water Storage Duration Curve (TDC) and Total Storage Deficit (TSD):

To simplify the information available for judging the characteristics of TWS, we express the TWS changes as a single value through the use of the TWS duration curve (TDC). The TDC is derived through the principle of the Flow Duration Curve (FDC). The FDC is a frequency distribution formed from daily/monthly stream flow data and their exceedence probability (Yadav et al., 2007). In this approach, all the available data are first listed in descending order and given a rank (the maximum will take the value 1 and the minimum will take the last rank). Using the ranks $m$, the probability of exceedence (in percentage) is computed using the Weibul method (Helsel \& Hirsch, 2002, p. 23):

$$
\text { Exceedence } \%=\frac{m}{(N+1)} \times 100,
$$

where $m$ is rank and $N$ is the sample size. TDC is obtained by plotting the TWS against its probability of exceedence. The slope $S_{T D C}$ of the TDC is then calculated between the 33rd and 66th TWS percentiles using

$$
S_{T D C}=\frac{T W S(33 \%)-T W S(66 \%)}{66-33}
$$

modified for the TWS case from Sawicz et al. (2011) as this portion represents a relatively linear part of the TDC. This slope reflects the aquifer storage size and the aquifer through flow property. 
To infer on the TWS depletion, Total Storage Deficit Index (TSDI) for each region was computed from GRACE derived TWS anomalies as (Yirdaw et al., 2008):

$$
T S D_{j}=\frac{T W S_{j}-\operatorname{Mean}\left(T W S_{j}\right)}{\operatorname{Max}\left(T W S_{j}\right)-\operatorname{Min}\left(T W S_{j}\right)} \times 100,
$$

where $T D S_{j}$ is the total storage deficit (\%); $T W S_{j}$ is the monthly total storage anomaly as derived from GRACE-measurements, $\operatorname{Mean}\left(T W S_{j}\right), \operatorname{Max}\left(T W S_{j}\right)$, and $\operatorname{Min}\left(T W S_{j}\right)$ are the long term mean, maximum, and minimum $T W S$, respectively, for each month $j$ over the study period (2003-2011).

(iii) Cross-correlation Analysis:

To study the lag time of water storage variations (TWS and soil moisture) in response to rainfall, lagged correlation analyses at $95 \%$ confidence level were carried out between (a) TWS and rainfall, (b) soil moisture variation and rainfall, and (c) soil moisture anomalies and TWS.

(iv) Principal Component Analysis (PCA):

Principal Component Analysis (PCA) is a statistical technique that can be used to extract dominant uncorrelated patterns from spatio-temporal observations (Preisendorfer, 1988). In principle, PCA expands the derived TWS changes within the 10 defined regions in terms of new sets of orthogonal vectors know as empirical orthogonal functions (EOFs) associated with their uncorrelated temporal evolutions known as principal components (PCs) (Forootan \& Kusche, 2012). The PCA method used in this paper is based on the eigenvalue decomposition of the data-derived auto-covariance matrix (Preisendorfer, 1988). In this study, only the dominant components of TWS behaviour over Ethiopia are shown. The less dominant components that most often correspond to lower correlations with overall TWS changes are not presented. To decide on the significant number of modes, North's rule of thumb, which states that if the sampling error of a particular eigenvalue is comparable to a nearby eigenvalue, then the sampling errors in the EOF will be comparable to the "nearby" EOF (North et al., 1982) was used (see Preisendorfer (1988) for details). 


\section{Results}

Figure 3 shows box plots used to highlight the overall patterns of response for the variations in water storage over Ethiopia computed from GRACE, soil moisture (from GLDAS), and rainfall (from TRMM) for the 10 sub-regions over the study period (2003-2011). The lower whisker of the box plot indicates the lowest observed value (sample minimum), the lower end of the box is the lower quartile (25\%), the line across the box indicates the median, the upper end of the box specify the upper quartile (75\%), and the upper whisker of the plot illustrates the highest observed value of the sample. The red crosses indicate outliers that represent cases that have values more than three times the height of the boxes. Overall, the results in Fig. 3 (top) show that the variation in TWS is greatest in the western highlands area (see Fig. 1), i.e., western (region 2), north-western (region 3), and northern (region 4) of Ethiopia, while the far eastern corner (region 10) shows relatively low variation. Highland dominated regions (Fig. 3, middle and bottom, regions 2, 3, 4 and 5) show strong variations in soil moisture and rainfall, while the lowland dominated segments display comparatively less variability (Fig. 3, middle and bottom).

\subsection{Dominant Variability of Water-Storage over Ethiopia}

The PCA method was applied to the TWS, soil-moisture, and precipitation fields derived for the 10 sub-regions (Fig. 4) in order to identify patterns of simultaneous temporal variations in the whole country rather than any localization of the signal.. Applying North's rule of thumb shows that for the three data sets above, only the first two components are statistically significant, which are shown in Fig. 4. The first mode of PCA on TWS (EOF1 and PC1) is equivalent to $65.83 \%$ of total TWS variability, with PC1 showing a dominant annual variability and EOF1 showing that regions 2, 3, 4 and 5 are the dominant. Note that the PCA/EOF results are somewhat close to the regions that show predominant variability shown in Fig. 3a, as one could expect. The same statement is also true for the first mode of soil-moisture (67.4\% of variance) and 


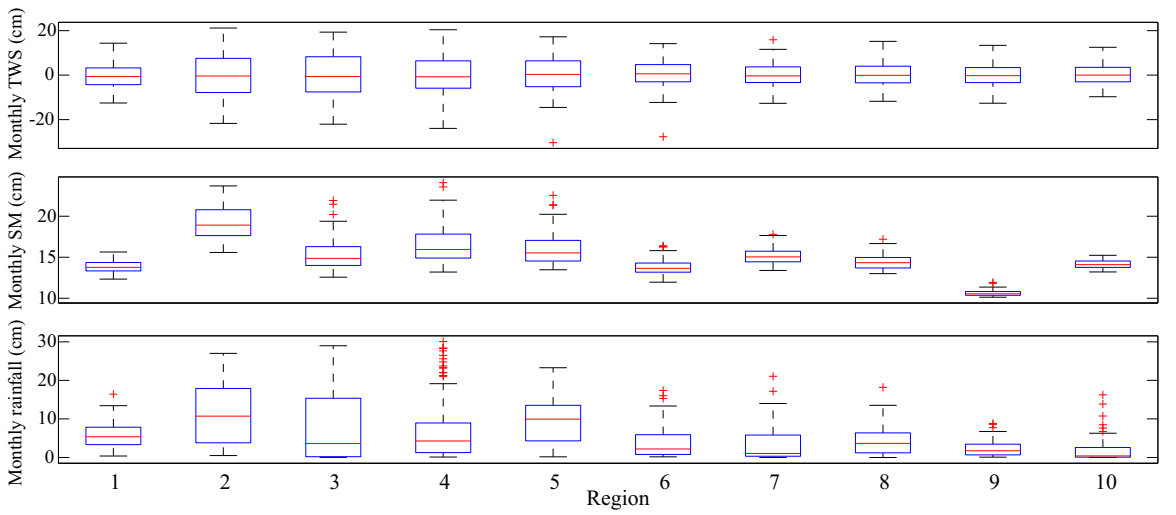

Figure 3: Summary of TWS, soil moisture, and rainfall variatiability for each of the Ethiopian region shown in Fig. 2. The red crosses indicates outliers. TWS (top) is seen to be greatest in western (region 2), north-western (region 3) and northern (region 4)region and less so in the far east (region 10). Regions 2, 3, 4 and 5 (central) show a strong variation in soil moisture (middle) and rainfall (bottom).

rainfall ( $70.1 \%$ of variance). The second modes of all three data sets extract mostly inter-annual variability in the data. There are also some annual and intra-annual variations detectable in the second modes, which are due to the incapability of the PCA method to perfectly separate such signals (Forootan \& Kusche, 2012).

The second mode (EOF2 and PC2) of the TWS (Fig 4) is equivalent to $14.9 \%$ of the total variance and shows that the regions $2,3,6,7,8$ and 9 are dominant. The dominant inter-annual soil moisture variations are found in regions 1, 2, 58, and 10 (EOF2 and PC2 of soil-moisture in Fig. 4, middle). Finally, the same regions, i.e., 1, 2, 5-8, and 10 are also found to exhibit the most inter-annual precipitation (EOF2 and $\mathrm{PC} 2$ of rainfall in Fig. 4, right), again confirming our findings in Fig. 3a. We should mention that the accuracy of the annual and semi-annual GRACE-TWS estimations are around $1 \mathrm{~cm}$ (in amplitude) for the selected $4^{\circ} \times 4^{\circ}$ regions. This has also been tested by considering the sampling errors originating from length-limited data sets (Preisendorfer, 1988, p. 199), as well as the coefficients errors, provided by the data producer, the 
GFZ Potsdam Centre (the error-bars are not shown here in order to enhance the visual interpretation of the patterns).
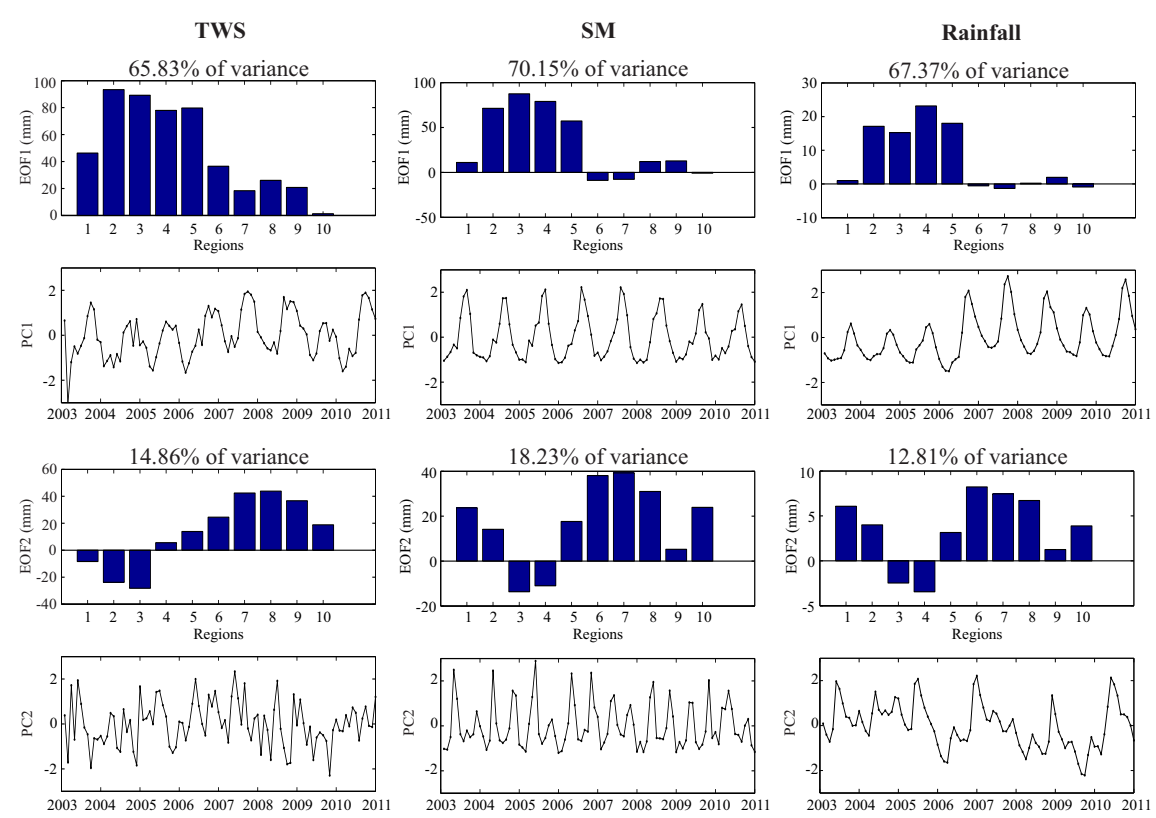

Figure 4: Results of PCA, derived from its application to time series of the 10 predefined regions in Fig. 2. TWS data from GRACE (left), soil moisture data from GLDAS (middle) and, rainfall data from TRMM (right).

392

\subsection{Annual and Seasonal Mean TWS Changes}

Figure 5 depicts the mean water mass lost or gained in $\mathrm{cm} /$ month aggregated over seasonal and annual time scales from monthly GRACE-derived TWS values over the study period. The results of the seasonal analysis of TWS show regions $1,2,3,4$ and 5 having the same characteristics, where they experienced a decrease in TWS during winter and spring and gained it during summer and autumn. Regions 7 and 8 reflect the same characteristics as the first group, but differ in that their main water loss season is during winter and the water gain in summer (Fig. 5, top). The other three regions (region 6, 9, and 10) have different characteristics from all the others. The only characteristic that regions 

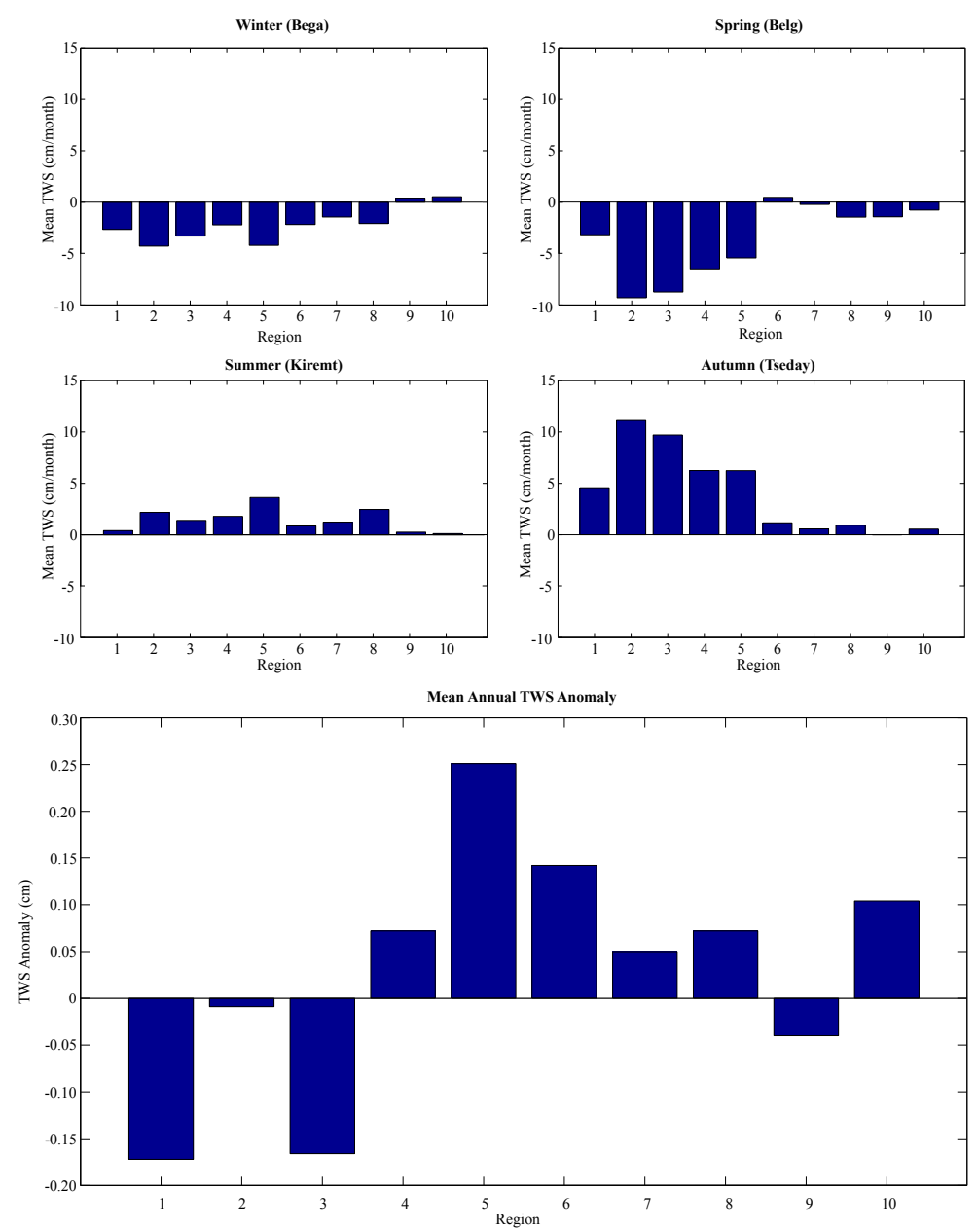

Figure 5: Seasonal (top) and Annual (bottom) means of TWS variation over Ethiopia derived from GRACE product for the study period (2003-2011). In brackets are the Ethiopian names for the seasons, Bega (December-February), Belg (March May), Kiremt (June-August) and Tseday (September-November), see Section 2.

The annual mean indicates that mass has been gained in the northern (region 
4), central and eastern (regions 5 and 8 respectively), southern (regions 6 and 7 ) and far eastern (region 10) regions, while the south-western (regions 1), western (region 2), north-western (region 3), and north-eastern (region 9) regions showed that mass has been lost (Fig. 5, bottom). The maximum mean annual water mass gains were recorded in central Ethiopia (region 5) during summer (Fig. 5), which may be attributed to three main factors. First, the larger part of the Rift Valley basin lakes lies in this region (see Figs. 1 and 2), and could be exerting a greater surface water influence. The Ethiopian rift valley lakes' basin (Fig. 1), which lies in the main Ethiopian Rift, is a collection of cascade lakes, which might have underground connections with other lakes. However, regarding the second factor, considering the amount of surface water, the rift valley lakes' basin is known to have a closed watershed, and as such there is water going into the lakes, but have no surface water outlets, e.g., Lake Naivasha (Awange et al., 2013a). Thirdly, the region is again the starting point of four of the six Ethiopian international basins that include the Awash, Omo-Ghibe, GanaleDawa and Wabishebele.

The GRACE-derived TWS duration curve (TDC, see Eqn. 2) is presented in Fig. 6. From the probability of exceedence at the no loss/no gain point (i.e., point at which the TWS anomaly equals zero), it can be seen that almost all regions gained water mass only $45 \%$ of the time, and lost it $55 \%$ of the time. The TDC curves in Fig. 6 also allow us to reflect upon the probability of change in amount of TWS. For, example, the maximum water mass gain, which has a probability of occurrence of less than $1 \%$ over the study period, ranges from 12 $\mathrm{cm} /$ month in region 10 to $21 \mathrm{~cm} /$ month in region 2 , while the maximum water loss with a percentage exceedence of about $99 \%$ ranges from $30 \mathrm{~cm} / \mathrm{month}$ in region 5 to $10 \mathrm{~cm} /$ month in region 10 .

To quantify the TWS changes into a single value, the slope of the TDC was calculated using equation 4. A high slope value means rapid response and small storage potential, while a low slope value means slow response to incoming water mass and large storage potential. For simplicity, we can group the regions based on their TDC slopes as, i) $S_{T D C}>30 \%$ (only region 2 ), ii) $20 \%<S_{T D C}<30 \%$ 


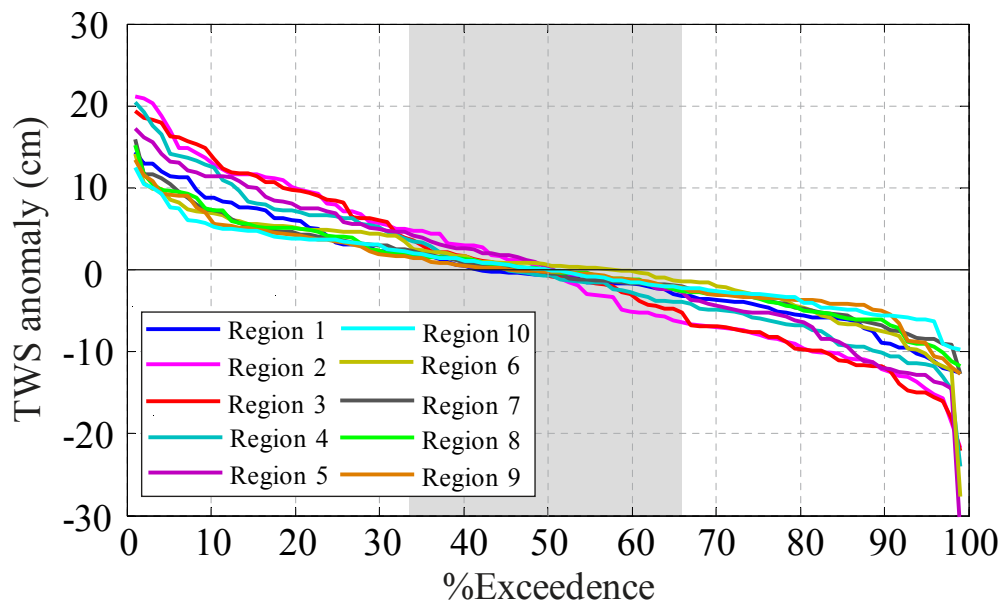

Figure 6: Total Duration Curve (TDC) of the GRACE-based monthly TWS anomalies over the study period. The figure indicates that almost all regions gained water $45 \%$ of the time. Slope analysis of this figure show that over Ethiopia, TWS changes are high in the western region and low in the eastern region. The extreme fall at the end of the curves for regions 5 and 6 could be the consequence of the loss of a large amount of water in January and February 2003, which was the result of drought that propagated from the previous year.

(regions 3, 4 and 5) and iii) $10 \%<S_{T D C}<20 \%$ (regions 1, 6, 7, 8, 9 and 10). This indicates that over Ethiopia, the TWS changes are highest in the western region and lowest in the north-eastern region, i.e., consistent with the findings in Figs. 3 and 4.

\subsection{Inter-annual Variation}

Changes in TWS, soil moisture (SM), rainfall, and groundwater storage (GW) anomalies over the study period for each month have been compiled in Fig. 7. The year to year changes in TWS (Fig. 7(a)) shows that except for a few months, e.g., June (regions 1, 4 and 9), July (regions, 7 and 8) and September (region 6), there exist significant variability in TWS in all regions for each month. Figure 7(b) also show considerable variations in soil moisture for all months, where it is relatively strong during rainy seasons. The inter-annual plot of rainfall illustrated in Fig. 7(c) describes the considerable variation that exists in all months in regions 1 and 2, while regions 3-5, 8 and 9 show relatively 
low variability except during the major rainy season (June-September; JJAS). Additionally, there is a low variability in June-September for regions 6, 7 and 10, i.e., south east and east. The GW plots (Fig. $7(\mathrm{~d})$ ) present similar characteristics as the soil moisture and TWS. From Fig. 7, the variations of TWS, SM and GW anomalies are seen to be less correlated to rainfall for all regions with the exception of region 2 (western), see also Fig. 11.

\subsection{Intra-annual Variation}

Figure 8 shows the intra-annual variability of TWS, soil moisture, GW and rainfall developed from the mean of each month over the study period as opposed

to the red lines in Fig. 7. From this, one can clearly see two distinct groups based on the behaviour of their TWS anomaly values over the months. The first group includes regions 2, 3, 4 and 5, where the TWS and GW anomalies shows three similar parts; i) the rising limb, which occurs from June to September, indicating the recovery period of TWS, ii) the peak, which occurs in August, and iii) the recession or falling limb that covers a longer period than the previous ones, i.e., starting from a point at which the peak is attained and extending up to June. The results indicate that, like the rainfall patterns, TWS shows seasonality, having seasons showing mass gain (JJA and some parts of SON), while in the other two seasons, the mass loss exceeds the gain in most regions of Ethiopia. This happens since the mentioned periods are the main rainy seasons in Ethiopia. The second group includes all the other regions with characteristics opposite to the first group. That is, they have short duration recession curves with very long recovery or rising limb period, attaining their maximum peaks in the SON season. Despite the fact that SON is the long rainy period in these regions, the length of the rising period might be attributed to the aquifer type and size, as well as recharge mechanism. Compared to the rainfall, and the response of GW and TWS, one can see that there appears to be very little fluctuation in soil moisture in all cases.

Examining now the soil moisture in greater detail (Fig. 9), one can visually identify extreme regions that include (i) the western part of Ethiopia (i.e., region 
(a)

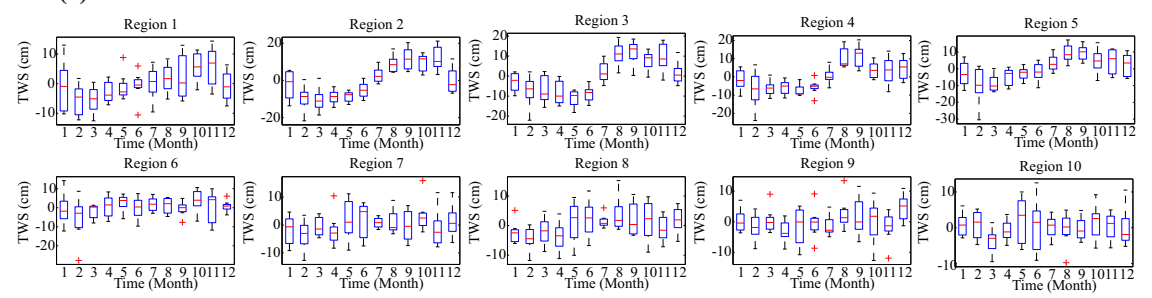

(b)

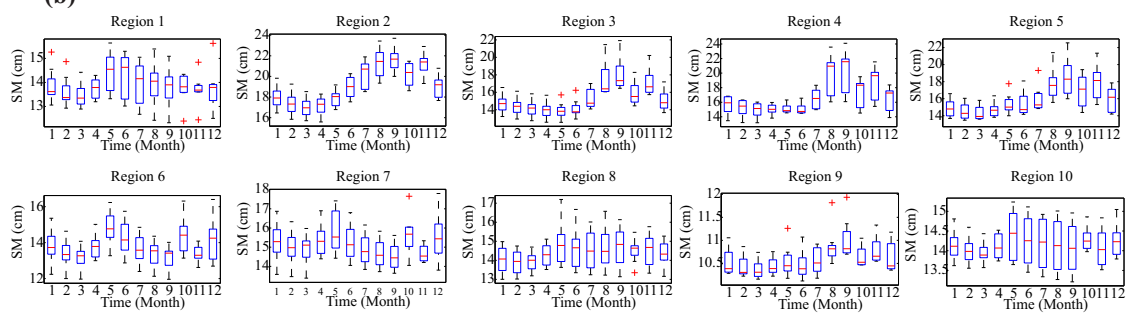

(c)

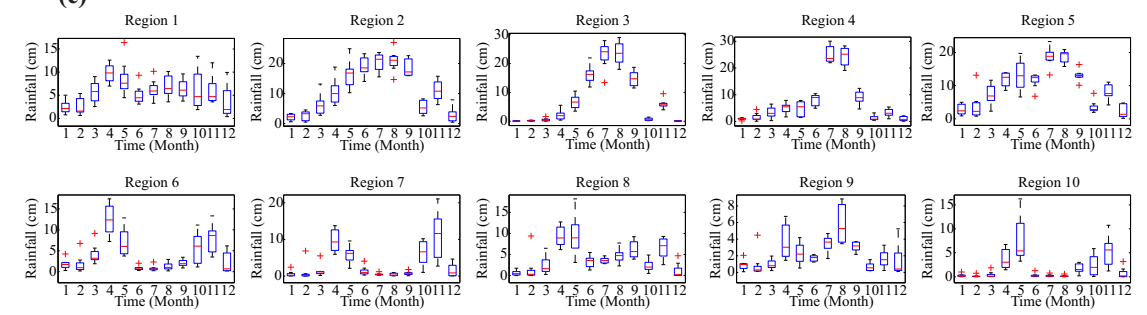

(d)

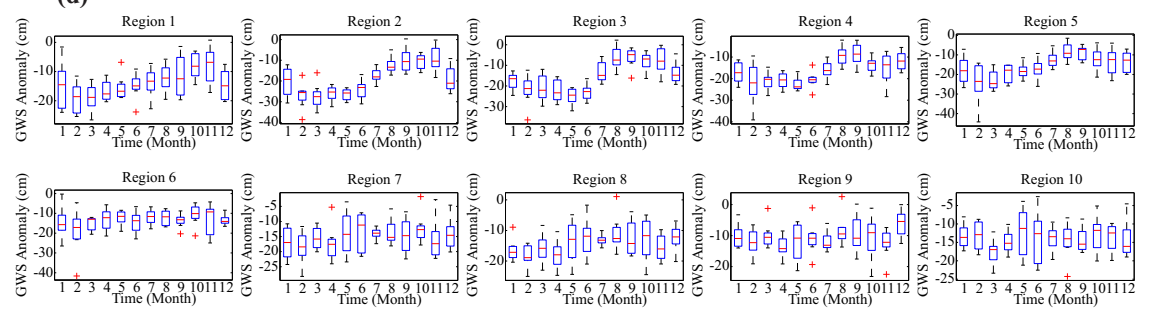

Figure 7: Inter-annual variability of TWS (a), Soil Moisture (b), Rainfall (c) and GW anomaly (d) over Ethiopia. The variation in TWS (a), soil moisture (b), and GW (d) are unrelated to the rainfall (c), thus indicating a possible human influence on hydrological changes in Ethiopia. Note the difference in amplitude of the figures. Although (a) and (d) look similar, they differ considerably in amplitude.

2), which has the highest soil moisture content of all the studied regions, (ii) the north-eastern (i.e., region 9), which has the lowest soil moisture content, and iii) the intermediate regions, which include all the other areas. Apart from this, 


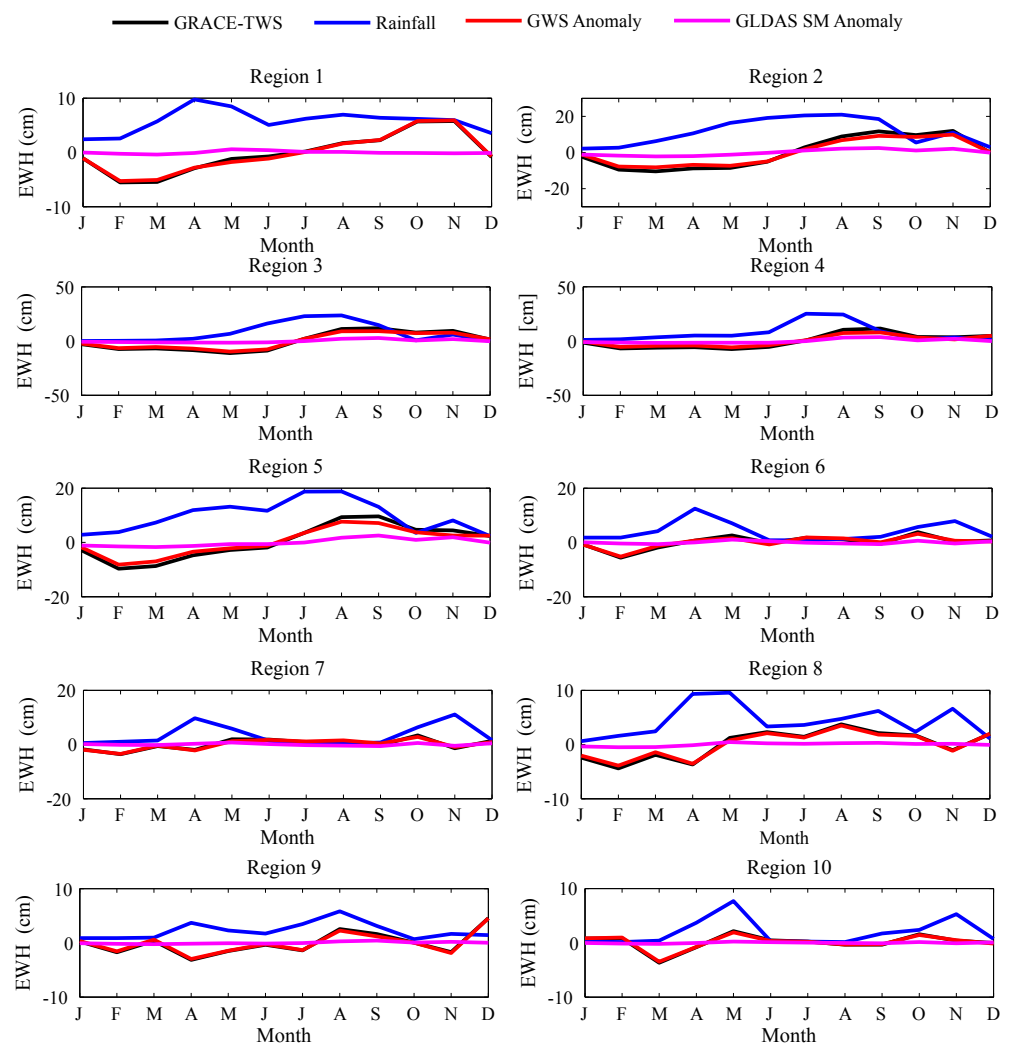

Figure 8: Intra-annual variability of the TWS, SM, GW and rainfall EWH (equivalent water height) over Ethiopia.

Ethiopia may be classified into three soil moisture variability regions. The first covers the western (region 2), north-western (region 3), northern (region 4) and central (region 5) sub-regions, which show little variability over the first half of the year, and then a significant rise in the second half, attaining their peaks in September. This is because the second half of the year is the main rainy season for most segments. The second soil moisture region (southern; region 6 and south-eastern; region 7) is characterized by the occurrence of two small peaks, one in May and the other in November, while the third soil moisture region includes the south-western (region 1) and eastern (region 10), displaying very little variability in soil moisture throughout the year compared to others.

The soil moisture variation over Ethiopia bears a resemblance to the agro- 


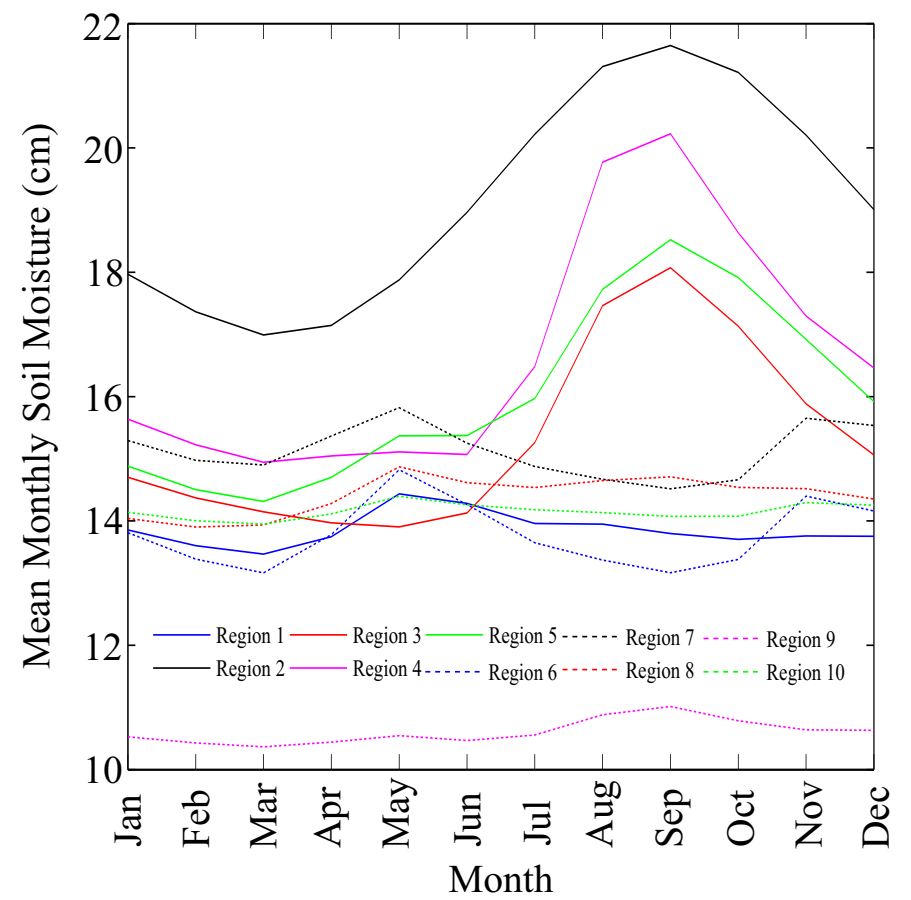

Figure 9: Intra-annual variability of soil moisture over Ethiopia.

ecological zonation described in Hurni (1988). Depending on the dominant agro-ecological zone in each region, three sub-divisions may exist. These are; (i) Dega/Woyna Dega consisting of regions 2, 4 and 5, (ii) the Bereha made up of regions 1, 6, 7, 8, 9 and 10, and (iii) the transitional zone Kolla/Dega, comprised only of region 3. The Dega/Woyna Dega group displays high soil moisture levels with strong seasonality, while the Bereha group shows little seasonality behavior as they receive little rainfall. Furthermore, Fig. 9 indicates two regions of comparatively extreme wetness and dryness, i.e., regions 2 and 9 , respectively. The possible reason for region 2's wetness is the fact that i) this region receives rainfall almost throughout the year, comprising the area which obtains the highest annual rainfall amount in Ethiopia (see section 2) and, ii) the land cover in the region is highly dominated by rainforest. In region 9 , the Danakil depression region, which shows much lower soil moisture content, is known to be one of the driest regions of Ethiopia, where there is no significant 
river flow and only short period bimodal rainfall, very scarce vegetation cover, and high temperatures (see Section 2). Ertale, the area where volcanic magma can be seen at Earth's surface is also in this region, where high temperatures, combined with little rainfall, lead to the retention time of water in the soil to be very limited.

\subsection{Correlation between Different Data Sets}

A correlation analysis between available data sets was made using the mean monthly data and is presented in Fig. 10 to study the time lag between rainfall and TWS, soil moisture and TWS, and soil moisture and rainfall. The analysis shows almost no lag between soil moisture and TWS in all regions, except regions 1 and 9, where lags of 5 and 1 month, respectively are seen. For TWS and rainfall, lags of 0 (region 10), 1 month (regions 4 and 7), 2 months (region 3), 3 months (regions 2, 5 and 8), 4 months (region 9), and 6 months (regions 1 and 6) have been observed, with strong correlations in regions 2, 3, 4 and 5. The lags between TWS and rainfall obtained from Fig. 10 are tabulated in Table 2. Larger lag periods are indicative of water-storages properties such as large groundwater reservoirs, indirect recharge mechanisms, or a combination of both, while smaller values are more likely to be attributed to direct recharge mechanisms, smaller groundwater reservoir or again a combination of them.

\subsection{Relationship between TRMM-Rainfall and GRACE-TWS}

From Figs. 7 and 8, one can see that there is little significant delineation between the plots of TWS and GW. It is, therefore, thought that the very large influence of TWS over Ethiopia comes from the groundwater storage. The relationship between rainfall and TWS is presented in Fig. 11. This is developed by accounting for the lag duration of TWS from rainfall. For example, in region 1, a lag of 6 months is used to assess how much of the rainfall observed in January contributed to the TWS in July. In all regions, except 2, 4 and 5, coefficients of determinant $R^{2}$ of less than 0.5 were obtained. For these regions, where high values of $R^{2}$ are obtained, i.e., the western (region 2), northern 


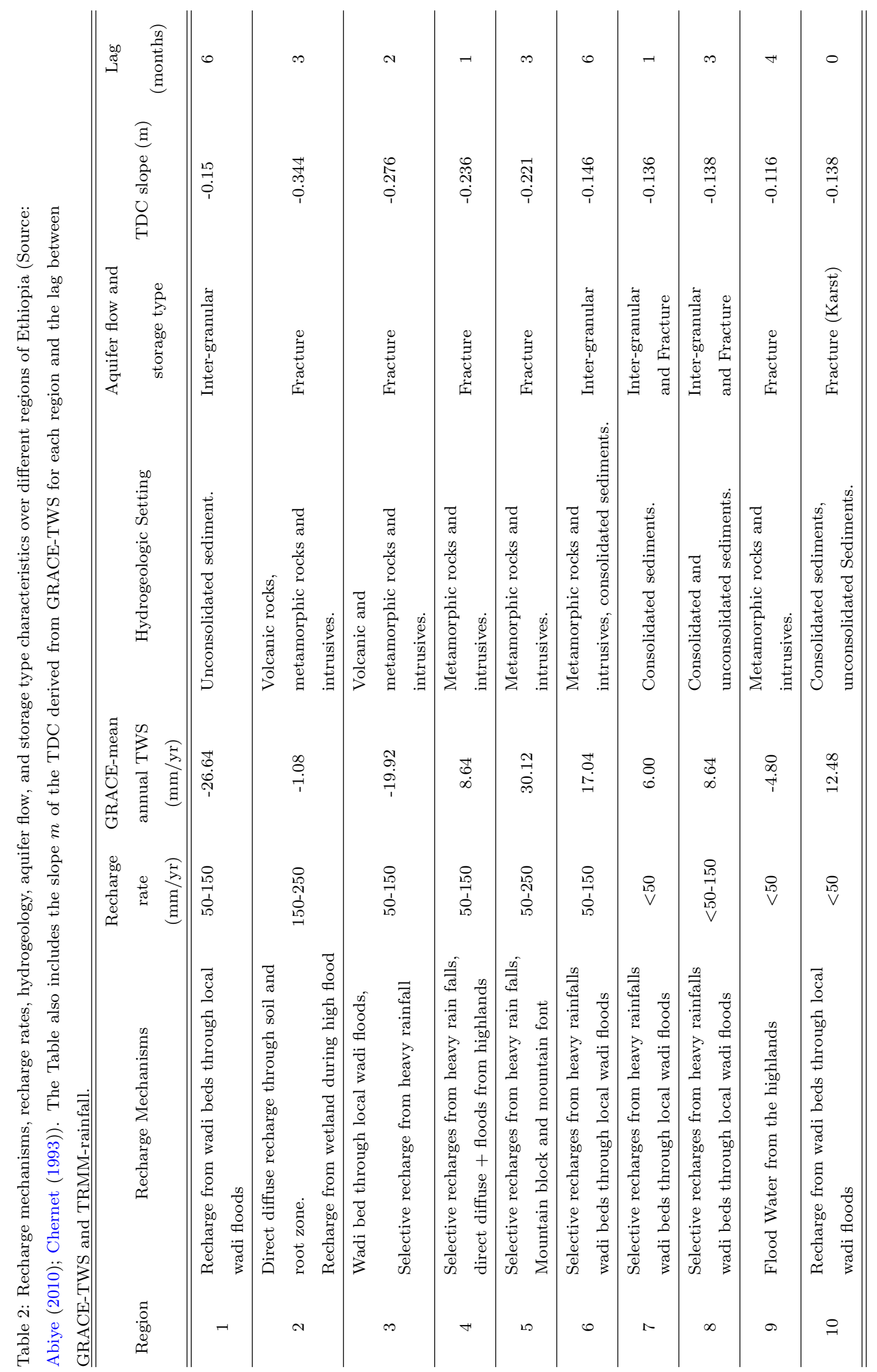




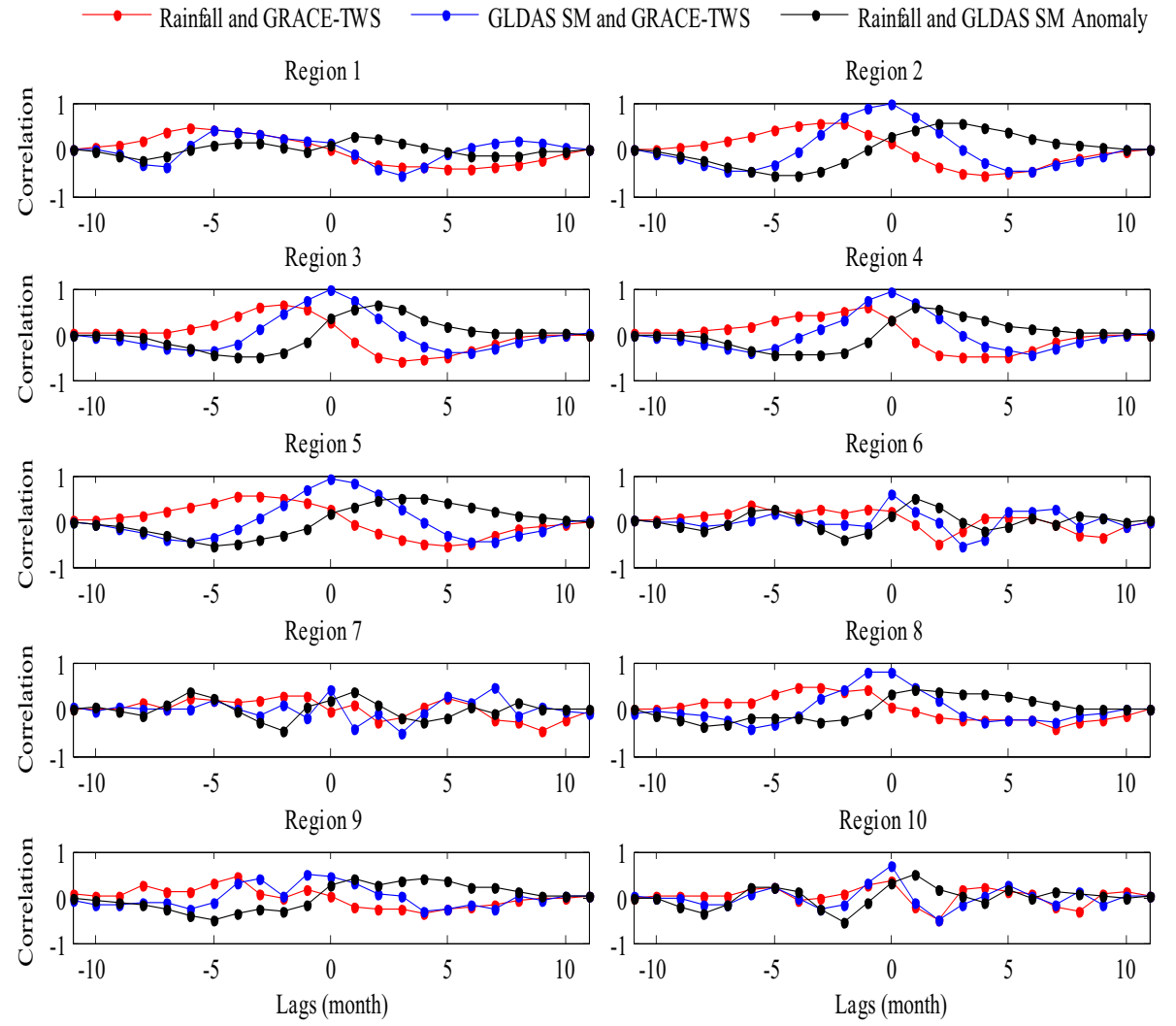

Figure 10: Correlation between different data sets (TWS, soil moisture, and rainfall) at 95\% confidence level.

(region 4) and central (region 5), two deductions could be made, i.e., i) either the regions are source of water (e.g., regions 2, 4 and 5) or, ii) the reliance of the groundwater storage variability on the rainfall pattern is minimal.

\section{Discussion}

\subsection{Topographic Impact on TWS}

As one can see from the results presented in Fig. 3 (top) and Fig. 4, the influence of topography on the TWS may be inferred. From these figures, the highland dominated regions of Ethiopia, i.e., the western highlands (Fig. 2, regions 2, 3, 4 and 5) show greater variability in TWS than the lowland-dominated 

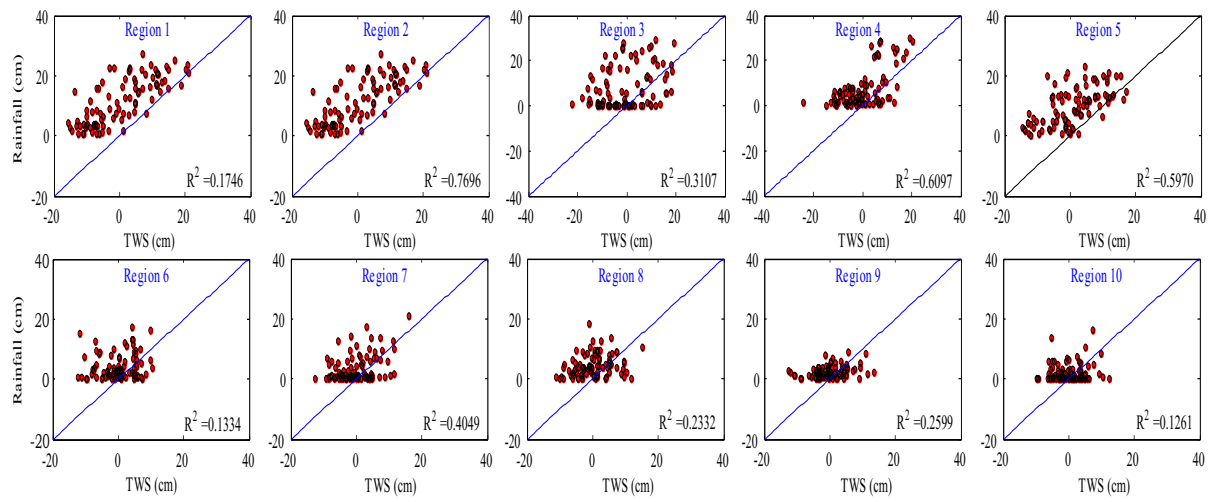

Figure 11: Relationship between TRMM rainfall in January and GRACE TWS in July for each region at a lag of six months. This lag is chosen as an example to show the impact of the January rainfall on TWS in July.

regions. In addition, from the lag correlation presented in Fig. 10, one can see the influence of the regime's hydrogeology on its response to rainfall. For instance, the karst dominated regions (i.e., 10 in Table 2) has zero lag while the unconsolidated sediment dominated region 1 has a lag of around 6 months.

However, hydrological fluxes are expected to differ greatly from the outlet to high elevations for some of the areas in the Ethiopian highlands. Whereas precipitation is expected to increase with elevation (depending on aspect), potential evapotranspiration decreases with elevation due to reduced temperatures at higher elevations (cf., Berhanu et al., 2013). Based on water balance estimates, runoff is therefore expected to be greater at higher elevation than lower ones for high gradient basins facing the prevailing storm movement direction. The total amount of runoff from the basin will therefore depend on the hypsometric relationship, i.e., the relative proportions of drainage area at different elevations. Since evapotranspiration will vary with the type of vegetation, changes in land use will also have a potential impact on the amount and type of evaporation (from either surface or groundwater sources). In addition, the conversion of relatively undisturbed (e.g., forested) areas to more intensive agriculture will greatly increase surface runoff at the expense of groundwater recharge due to 
reduced infiltration capacity. We therefore believe it is critical to assess the role of elevation in hydrological fluxes coupled with seasonal variability and changes under potential climate scenarios.

\subsection{Possible Human Influence on the Observed TWS}

Ethiopia is a highly populated region that has seen a number of dams constructed and high levels of water withdrawal from groundwater and surface water reservoirs, which would impact upon the total water storage (e.g., Berhane et al., 2013; Tesfagiorgis et al., 2011). Large scale land-use and land-cover changes in Ethiopia due to agricultural expansion and heavy grazing have been reported (e.g., Descheemaeker et al., 2009; Bewket \& Abebe, 2013). In addition, Hurni (1988) and Nyssen et al. (2004) have reported that land degradation is a serious problem to Ethiopia. Ethiopia is an agrarian country, where more than $85 \%$ of its population depend on irrigated agriculture, with production in certain regions being highly dependent on the available water resources (i.e., surface water and groundwater). The total area under irrigation in Ethiopia is about of 290,729 ha $(\sim 0.3 \%$ of the country's area), with about 2,611 ha depending on groundwater irrigation (Siebert et al., 2013). The irrigation water demand in Ethiopia is estimated to be $40 \mathrm{~km}^{3} /$ year (Egziabher, 2000), with an estimated 2.6-6.5 $\mathrm{km}^{3} /$ year of groundwater potential (Awulachew et al., 2007). The principal grain crops are wheat, barley (primarily cool-weather crops) and corn, sorghum, and millet (warm weather grain crops).

Since the GRACE products can resolve large areas to the tune of hundreds of $\mathrm{km}$ (i.e., $450 \mathrm{~km} \times 450 \mathrm{~km}$ ), the impact of anthropogenic activities at hill slope scales, such as those discussed in Descheemaeker et al. (2009), on its signals will not be detectable. However, if such impacts occur over a wider scale that is of the same order as the resolution of GRACE, then they may be detectable.

TSD in percent (Eq. (4)) are computed from the GRACE-derived TWS anomalies and presented in Fig. 12. Depending upon their TSD patterns, Ethiopia can be divided into three different zones. In the first zone, we have regions $2,3,4$, and 5, while regions 1 and 6 are in zone 2, with regions $7,8,9$ and 
10 in the third zone. For the three zones, TSD decreased from the beginning of 2003 until around mid-2006 for zones one and two, and January 2005 for the third zone. Then, for the first and third zones, it started to rise in 2006, while for the second group this was from around the beginning of 2007. The decrease in TSD starting from Jan-2003 indicates increasing dryness, which may be due to the propagation of the 2002 drought in Ethiopia (Anderson \& Choularton, 2004). In regions where significant TSD has been seen from 2003 to 2006 (e.g., Zone 1 in Fig. 12), the main crops are teff, sorghum, maize, wheat and millet. Despite the decrease in TSD in the regions, there has been an increase in crop production area and yield (Eberhardt, 2008), indicating on the one hand that such crops can be sustained under such water deficit conditions. However, on the other hand, this could indicate that the greater portion of this deficit in TWS could be due to groundwater storage depletion. This, however, remains an open question for future investigations.

In regions $1,2,3$, and 9 , over the study period, very significant water loss was identified (see Fig. 5, bottom), especially when compared to the recharge amount per year, as stated in Table 2. This might be attributed in part to human exploitation and partly due to climate impacts discussed below.

From the developed TDC using 96 months of GRACE derived TWS data (Fig. 6), the lower end of the curve might be due to extreme water depletion cases, while the upper end results from high rainfall condition with long return periods. This is again an open question subject to future investigations. Nonetheless, to see the real variation of TWS, the slope of the TDC in the region where one can assume linearity is computed. If this slope is expressed in percentage, it varies between $-14 \%$ to $-35 \%$. There are several factors that might affect the slope of the TDC, e.g., soil moisture, hydrogeological setting, aquifer flow, storage types, storage potential, recharge rates and recharge mechanisms. With the characteristics listed in Table 2, and their TDC slope, one notes that (i) region 2 has the smallest storage potential compared to the others, (ii) regions 3, 4 and 5 have intermediate storage potentials, and (iii) all the other regions have relatively large storage potentials. From Fig. 11, although 

and dominant indirect recharges.

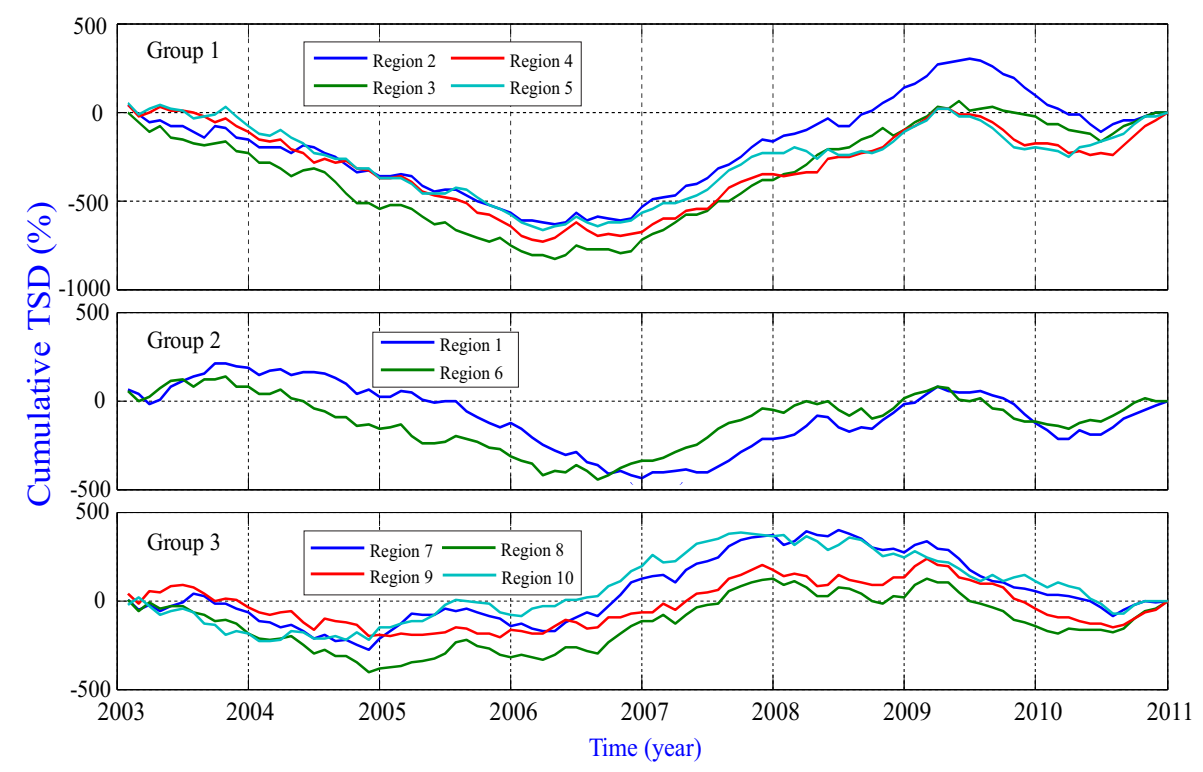

most regions have correlation coefficients of less than 0.5, Fig. 4 on the other hand show that certain regions gained TWS. This could indicate that a certain proportion of the TWS in the regions is contributed by subsurface inter flow

Figure 12: Total Storage Deficit (TSD) derived for the main 10 regions defined over Ethiopia subdivided into different zones. The values are in percent (see Eq. (4)).

\subsection{Climate Impact on the Observed TWS}

The extreme depletion in TWS and GW in certain regions during February 2003 (see PC1 of TWS in Fig. 4) could probably be due to the reported droughts in the year 2002 (Anderson \& Choularton, 2004). This is further supported when they are considered together with the lag determined from TWS and rainfall correlation (Fig. 10). Rainfall over Ethiopia is known to be seasonal, having dry and rainy seasons (Seleshi \& Zanke, 2004). The effect of this seasonality seems to be reflected in the TWS anomalies, having two distinct seasons on average, the water lose (winter, $21.3 \mathrm{~mm} / \mathrm{month}$ and spring, $36.6 \mathrm{~mm} / \mathrm{month}$ ) and water gain (summer, $14.4 \mathrm{~mm} /$ month and autumn, $41.0 \mathrm{~mm} / \mathrm{month}$ ) seasons. PCA 
results showed that the annual peaks of rainfall are also very important and are highly correlated to the annual peaks of TWS, thus indicating that rainfall is the main driving factor for the rise in TWS levels in most parts of Ethiopia. Although climatic factors such as drought could be a contributor towards the fall in TWS levels, as pointed out earlier, human influences may also contribute.

The dominant hydrogeologic regimes, recharge mechanisms, recharge rates, aquifer flow and storage types for each region are presented, e.g., in Chernet (1993) and Abiye (2010). Here we discuss the results obtained in relation to the properties of the regions described in the Table 2. The aquifers response lags to rainfall computed in this study are also listed in Table 2. For the same aquifer flow and storage type, one can notice that there are different lag values, see, e.g., regions 2 and 3 in Table 2, which could be attributed to the nature of the recharge mechanism in each region. Furthermore, regions that are dominated by the inter-granular aquifer flow and storage type are seen to have a longer lag periods (regions 1 , and 6), while karst dominated regions show a direct response to rainfall (region 10).

In the north-west (region 3) a lag of 2 months is noted (Table 2). This shows that it takes 2 months from when it rains to the time when the impact on TWS is visible, hence making the transfer of water from one season to another impossible. This implies that for most parts of Ethiopia, the rainfall in the previous season might have an impact on the TWS of the current season at most, but cannot have an effect later further. In regions 2, 5 and 8, the cross correlation between rainfall with TWS indicated a lag of 3 months (Table 2). Figure 11 also shows that there is a high correlation between rainfall and TWS in regions 2 and 5, indicating that the influence of rainfall on TWS in these regions is higher than subsurface inflow from adjacent regions. TWS in region 9 recorded a lag of 4 months from the rainfall (Table 2), although this region has low rainfall and also displays a poor correlation between rainfall and TWS anomaly (Fig. 11).

The mean annual rainfall for regions 1 and 6 have two small peaks, with a lag of 6 months obtained from the TWS/Rainfall cross correlation, implying 
that the autumn water gain is mainly from the rainfall received in winter. With the characteristics described in Table 2, these regions have the property of being able to transfer water mass gained from rainfall in a certain year to the next one. According to Kebede (2013), 3/4 of Ethiopia's aquifers receive localized and indirect recharge. This implies that only $1 / 4$ of Ethiopia's aquifers should exhibit a good correlation between TWS and rainfall. The $R^{2}$ results obtained from correlation analysis in Fig. 11 supports this assertion.

In the northern (region 4) and south eastern (region 7) regions, a lag of one month between TWS and rainfall was obtained from the cross correlation, implying that the aquifer responds to the rainfall after about one month. From the slopes of the TDC, region 4 has a lower storage potential than region 7 , while the rainfall in region 4 is a bit higher than in region 7. One may therefore conclude that the chance that water can be transferred from a rainy to nonrainy season in such regions is very low. In this case, the rise or fall in TWS in certain season is mostly subject to the rainfall for that particular season.

\section{Conclusions}

Time series of terrestrial water storage anomalies (TWS), soil moisture, and rainfall over Ethiopia were derived from GRACE, GLDAS, and TRMM data sets and products, respectively, and analyzed with the aim of better understanding the relationship between rainfall and groundwater variations over Ethiopia's aquifers. The inter-annual and seasonal variability of water storage, the relationship between water storage changes with rainfall and soil moisture, and the aquifers' characteristics and TWS anomalies have been derived over a period of 8 years from 2003 to 2011 . The study indicates that the western part and the north-eastern lowland of Ethiopia are losing water. From seasonal analysis, the seasons when water is gained are found to be summer and autumn, while the loss seasons are spring and winter for most parts of Ethiopia. Soil moisture and rainfall variations showed the dominant annual water variability in the western, north western, northern and central regions, and the dominant seasonal vari- 
ability in the western and eastern regions. Change in soil moisture was seen to have less influence over the total water storage, while groundwater storage has a dominant influence. From a correlation analysis between TWS and rainfall, lags of 2 to 3 months for most regions were observed, indicating the capacity of a large portion of the Ethiopian groundwater storage (aquifers) to transfer water mass gained in certain periods to be less than 3 months. If validated at a finer spatial resolution, this could be vital information for water managers to know, that if an increase in TWS is required to back up water availability in dry seasons, one has to focus on increasing soil moisture and surface water storage rather than groundwater storages. The information could also be vital in land-use planning issues.

\section{Acknowledgment}

G. Wakbulcho thanks the United States Agency for International Development (USAID) for the financial support during the period of undertaking this research. He is further grateful to Arba Minch University (Ethiopia) for supporting his stay at EIWR. The authors thank the providers of GRACEGFZ, GLDAS and TRMM data used in this study. The authors are grateful to the Editor Prof Gabriel Katul and the three reviewers (Dr. Kevin Fleming and two anonymous reviewers) for their valuable comments that enriched the manuscript. This is a TIGeR publication No. 575.

\section{References}

Abiye, T. A. (2010). An overview of the transboundary aquifers in East Africa. Journal of African Earth Sciences, 58, 684-691. doi:10.1016/j · jafrearsci . 2009.10.003. Africa and the International Year of Planet Earth Promoting Earth sciences-based decision making in Africa 22nd Colloquium of African Geology.

Alemayehu, T. (2006). Groundwater occurrence in Ethiopia. Addis Ababa, Ethiopia: Addis Ababa University. 
Anderson, S., \& Choularton, R. (2004). Retrospective analysis: 2002/3 crisis in Ethiopia: early warning and response. Technical Report The Regional Economic Development Services Office For East and Southern Africa (REDSO).

Awange, J., Forootan, E., Kuhn, M., Kusche, J., \& Heck, B. (2014). Water storage changes and climate variability within the nile basin between 20022011. Advances in Water Resources, (pp. -). doi:10.1016/j.advwatres. 2014.06.010.

Awange, J., Forootan, E., Kusche, J., Kiema, J., Omondi, P., Heck, B., Fleming, K., Ohanya, S., \& Gonçalves, R. (2013a). Understanding the decline of water storage across the Ramser-Lake Naivasha using satellite-based methods. $A d$ vances in Water Resources, 60, 7-23. doi:10.1016/j.advwatres.2013.07. 002.

Awange, J. L. (2012). Environmental monitoring. In Environmental Monitoring using GNSS Environmental Science and Engineering (pp. 1-12). Springer Berlin Heidelberg. doi:10.1007/978-3-540-88256-5_1.

Awange, J. L., Anyah, R., Agola, N., Forootan, E., \& Omondi, P. (2013b). Potential impacts of climate and environmental change on the stored water of lake victoria basin and economic implications. Water Resources Research, 49, 8160-8173. doi:10.1002/2013WR014350.

Awange, J. L., \& Kyalo Kiema, J. B. (2013). Environmental Monitoring and Management. Environmental Science and Engineering. Springer Berlin Heidelberg. doi:10.1007/978-3-642-34085-7_1.

Awange, J. L., Sharifi, M. A., Ogonda, G., Wickert, J., Grafarend, E. W., \& Omulo, M. A. (2008). The falling Lake Victoria water level: GRACE, TRIMM and CHAMP Satellite Analysis of the Lake Basin. Water Resources Management, 22, 775-796. doi:10.1007/s11269-007-9191-y.

Awulachew, S., Yilma, A., Loulseged, M., Loiskandl, W., Ayana, M., \& Alamirew, T. (2007). Water resources and irrigation development in Ethiopia. 
Working Paper 123 International Water Management Institute Colombo, Sri Lanka.

Ayenew, T., Demlie, M., \& Wohnlich, S. (2008). Hydrogeological framework and occurrence of groundwater in the Ethiopian aquifers. Journal of African Earth Sciences, 52, 97-113. doi:10.1016/j.jafrearsci.2008.06.006.

Berhane, G., Martens, K., Farrah, N. A., \& Walraevens, K. (2013). Water leakage investigation of micro-dam reservoirs in Mesozoic sedimentary sequences in Northern Ethiopia. Journal of African Earth Sciences, 79, 98-110. doi:http://dx.doi.org/10.1016/j.jafrearsci.2012.10.004.

Berhanu, B., Melesse, A. M., \& Seleshi, Y. (2013). GIS-based hydrological zones and soil geo-database of Ethiopia. $\{$ CATENA\}, 104, 21-31. doi:10.1016/j . catena.2012.12.007.

Bewket, W., \& Abebe, S. (2013). Land-use and land-cover change and its environmental implications in a tropical highland watershed, Ethiopia. International Journal of Environmental Studies, 70, 126-139. doi:10.1080/ 00207233.2012 .755765 .

Bewket, W., \& Conway, D. (2007). A note on the temporal and spatial variability of rainfall in the drought-prone amhara region of ethiopia. International Journal of Climatology, 27, 1467-1477. doi:10.1002/joc.1481.

Beyene, E. G., \& Meissner, B. (2010). Spatio-temporal analyses of correlation between $\{\mathrm{NOAA}\}$ satellite $\{\mathrm{RFE}\}$ and weather stations' rainfall record in Ethiopia. International Journal of Applied Earth Observation and Geoinformation, 12, Supplement 1, S69-S75. doi:10.1016/j.jag.2009.09.006. Supplement Issue on "Remote Sensing for Africa - A Special Collection from the African Association for Remote Sensing of the Environment (AARSE)".

Bonsor, H. C., Mansour, M. M., MacDonald, A. M., Hughes, A. G., Hipkin, R. G., \& Bedada, T. (2010). Interpretation of grace data of the nile basin 
using a groundwater recharge model. Hydrology and Earth System Sciences Discussions, 7, 4501-4533. doi:10.5194/hessd-7-4501-2010.

Chernet, T. (1993). Hydrogeology of Ethiopia and water resources development. Technical Report Ethiopian Institute of Geological Surveys, Ministry of Mines and Energy Addis Ababa, Ethiopia.

Cheung, W. H., Senay, G. B., \& Singh, A. (2008). Trends and spatial distribution of annual and seasonal rainfall in Ethiopia. International Journal of Climatology, 28, 1723-1734. doi:10.1002/joc.1623.

Chukalla, A., Haile, A., \& Schultz, B. (2013). Optimum irrigation and pond operation to move away from exclusively rainfed agriculture: the Boru Dodota Spate Irrigation Scheme, Ethiopia. Irrigation Science, 31, 1091-1102. doi:10. 1007/s00271-012-0390-9.

Conway, D., \& Schipper, E. L. F. (2011). Adaptation to climate change in Africa: Challenges and opportunities identified from Ethiopia. Global Environmental Change, 21, 227-237. doi:10.1016/j.gloenvcha.2010.07.013.

Descheemaeker, K., Raes, D., Nyssen, J., Poesen, J., Haile, M., \& Deckers, J. (2009). Changes in water flows and water productivity upon vegetation regeneration on degraded hillslopes in northern Ethiopia: a water balance modelling exercise. The Rangeland Journal, 31, 237-249. doi:10.1071/RJ09010.

Dinku, T., Ceccato, P., Grover?Kopec, E., Lemma, M., Connor, S. J., \& Ropelewski, C. F. (2007). Validation of satellite rainfall products over East Africa's complex topography. International Journal of Remote Sensing, 28, 1503-1526. doi:10.1080/01431160600954688.

Dinku, T., Chidzambwa, S., Ceccato, P., Connor, S. J., \& Ropelewski, C. F. (2008). Validation of high-resolution satellite rainfall products over complex terrain. International Journal of Remote Sensing, 29, 4097-4110. doi:10. 1080/01431160701772526. 
Dinku, T., Pietro, C., Keith, C., \& Stephen, J. C. (2010). Evaluating detection skills of satellite rainfall estimates over desert locust recession regions. Journal of Applied Meteorology and Climatology, 49, 1322-1332. doi:10.1175/2010JAMC2281. 1.

Eberhardt, M. (2008). Cereal production in Ethiopia: A brief historical overview of land under cultivation and yields. URL: http://users.ox.ac . uk/ econstd/Brief_MEberhardt.pdf.

Egziabher, T. G. (2000). Regional development planning in Ethiopia: Past experience, current initiatives and future prospects. Eastern Africa Social Science Research Review, 16, 65-94.

Engida, A. N., \& Esteves, M. (2011). Characterization and disaggregation of daily rainfall in the Upper Blue Nile Basin in Ethiopia. Journal of Hydrology, 399, 226-234. doi:10.1016/j.jhydrol.2011.01.001.

Famiglietti, J. S., \& Rodell, M. (2013). Water in the balance. Science, 340, 1300-1301. doi:10.1126/science.1236460.

Fang, H., Beaudoing, H. K., Rodell, M., Teng, W. L., \& Vollmer, B. E. (2009). Global Land Data Assimilation System (GLDAS) Products, Services and Application from NASA Hydrology Data and Information Services Center (HDISC). In ASPRS 2009 Annual Conference. Baltimore, Maryland.

FAO (2005). Irrigation in Africa in figures: AQUASTAT Survey - 2005. FAO Water Reports 29 Food and Agriculture Organization of the United Nations Rome. Edited by Karen Frenken.

Ferguson, A., \& Harbott, B. (1982). Geophysical, Physical and Chemical aspects of Lake Turkana. In E. Hopson (Ed.), Lake Turkana: A report of the findings of the Lake Turkana project 1972-1975. London, UK: Overseas Development Administration.

Fleming, K., \& Awange, J. L. (2013). Comparing the version 7 TRMM 3B43 monthly precipitation product with the TRMM 3B43 version 6/6A and Bu- 
reau of Meteorology datasets for Australia. Australian Meteorological and Oceanographic Journal, 63, 421-426. URL: http://www.bom.gov.au/amm/ docs/2013/fleming.pdf.

Forootan, E., Awange, J., Kusche, J., Heck, B., \& Eicker, A. (2012). Independent patterns of water mass anomalies over Australia from satellite data and models. Remote Sensing of Environment, 124, 427-443. doi:10.1016/j.rse.2012.05.023.

Forootan, E., \& Kusche, J. (2012). Separation of global time-variable gravity signals into maximally independent components. Journal of Geodesy, 86, 477-497. URL: 10.1007/s00190-011-0532-5. doi:10.1007/ s00190-011-0532-5.

Forootan, E., Rietbroek, R., Kusche, J., Sharifi, M., Awange, J., Schmidt, M., Omondi, P., \& Famiglietti, J. (2014). Separation of large scale water storage patterns over iran using GRACE, altimetry and hydrological data. Remote Sensing of Environment, 140,580-595. doi:10.1016/j.rse.2013.09.025.

Furi, W., Razack, M., Abiye, T. A., Kebede, S., \& Legesse, D. (2012). Hydrochemical characterization of complex volcanic aquifers in a continental rifted zone: the Middle Awash basin, Ethiopia. Hydrogeology Journal, 20, 385-400. doi:10.1007/s10040-011-0807-1.

Helsel, D., \& Hirsch, R. (2002). Statistical Methods in Water Resources Techniques of Water Resources Investigations volume chapter A3 of Book 4. U.S. Geological Survey.

Huffman, G. J., \& Bolvin, D. T. (2012). TRMM and other data precipitation data set documentation. URL: ftp://meso-a.gsfc.nasa.gov/pub/ trmmdocs/3B42_3B43_doc.pdf (visited on 2012-03-23).

Huffman, G. J., Bolvin, D. T., Nelkin, E. J., Wolff, D. B., Adler, R. F., Gu, G., Hong, Y., Bowman, K. P., \& Stocker, E. F. (2007). The TRMM multisatellite precipitation analysis (TMPA): Quasi-global, multiyear, combined-sensor 
precipitation estimates at fine scales. Journal of Hydrometeorology, 8, 3855 . doi:10.1175/JHM560.1.

Hurni, H. (1988). Agroecological Belts of Ethiopia: Explanatory notes on three maps at a scale of 1:1,000,000. Research Report Centre for Development and Environment University of Bern, Switzerland in association with The Ministry of Agriculture, Ethiopia Bern. Soil Conservation Research Programme Ethiopia.

Kebede, S. (2013). Groundwater in Ethiopia: Features, Numbers and Opportunities. Springer Hydrogeology. Springer Berlin Heidelberg.

Kebede, S., Travi, Y., Alemayehu, T., \& Ayenew, T. (2005). Groundwater recharge, circulation and geochemical evolution in the source region of the Blue Nile River, Ethiopia. Applied Geochemistry, 20, 1658-1676. doi:10. 1016/j. apgeochem.2005.04.016.

Kebede, S., Travi, Y., Asrat, A., Alemayehu, T., Ayenew, T., \& Tessema, Z. (2008). Groundwater origin and flow along selected transects in Ethiopian rift volcanic aquifers. Hydrogeology Journal, 16, 55-73. doi:10.1007/ s10040-007-0210-0.

Kummerow, C., William, B., Toshiaki, K., James, S., \& Simpson, J. (1998). The tropical rainfall measuring mission (TRMM) sensor package. Journal of Atmospheric and Oceanic Technology, 15, 809-817. doi:10.1175/ 1520-0426(1998)015<0809: TTRMMT>2 . 0. CO; 2.

Kusche, J. (2007). Approximate decorrelation and non-isotropic smoothing of time-variable GRACE-type gravity field models. Journal of Geodesy, 81, 733-749. doi:10.1007/s00190-007-0143-3.

Kusche, J., Schmidt, R., Petrovic, S., \& Rietbroek, R. (2009). Decorrelated GRACE time-variable gravity solutions by GFZ, and their validation using a hydrological model. Journal of Geodesy, 83, 903-913. doi:10.1007/ s00190-009-0308-3. 
Liu, Z., Ostrenga, D., Teng, W., \& Kempler, S. (2012). Tropical Rainfall Measuring Mission (TRMM) precipitation data and services for research and applications. Bulletin of the American Meteorological Society, 93, 1317-1325. doi:10.1175/BAMS-D-11-00152.1.

Longuevergne, L., Scanlon, B. R., \& Wilson, C. R. (2010). GRACE Hydrological estimates for small basins: Evaluating processing approaches on the High Plains Aquifer, USA. Water Resources Research, 46, n/a-n/a. doi:10.1029/ 2009WR008564.

Marshall, M., Funk, C., \& Michaelsen, J. (2012). Examining evapotranspiration trends in africa. Climate Dynamics, 38, 1849-1865. doi:10.1007/ s00382-012-1299-y.

Melesse, A., Abtew, W., Dessalegne, T., \& Wang, X. (2010). Low and high flow analyses and wavelet application for characterization of the Blue Nile River system. Hydrological Processes, 24, 241-252. doi:10.1002/hyp.7312.

Melesse, A. M. (Ed.) (2011). Nile River Basin: Hydrology, Climate and Water Use. Springer Netherlands.

Mengistu, D., Bewket, W., \& Lal, R. (2013). Recent spatiotemporal temperature and rainfall variability and trends over the upper blue nile river basin, ethiopia. International Journal of Climatology, (pp. n/a-n/a). doi:10.1002/ joc. 3837 .

MoWE (2012). Ministry of Water \& Energy of Federal Democratic Republic of Ethiopia. URL: http://www.mowr.gov.et/index.php?pagenum=2 . 1\&pagehgt=5495px (visited on 2012-11-05).

North, G. R., Bell, T. L., Cahalan, R. F., \& Moeng, F. J. (1982). Sampling errors in the estimation of empirical orthogonal functions. Monthly Weather Review, 110, 699706. doi:10.1175/1520-0493(1982) 110<0699: SEITEO>2 . 0 . CO; 2.

Nyssen, J., Clymans, W., Descheemaeker, K., Poesen, J., Vandecasteele, I., Vanmaercke, M., Zenebe, A., Van Camp, M., Haile, M., Haregeweyn, N., 
Moeyersons, J., Martens, K., Gebreyohannes, T., Deckers, J., \& Walraevens, K. (2010). Impact of soil and water conservation measures on catchment hydrological response - a case in north Ethiopia. Hydrological Processes, 24, 1880-1895. doi:10.1002/hyp.7628.

Nyssen, J., Poesen, J., Moeyersons, J., Deckers, J., Haile, M., \& Lang, A. (2004). Human impact on the environment in the Ethiopian and Eritrean highlands - a state of the art. Earth-Science Reviews, 64, 273-320. doi:10. 1016/S0012-8252(03)00078-3.

Omondi, P., Awange, J., Ogallo, L., Ininda, J., \& Forootan, E. (2013). The influence of low frequency sea surface temperature modes on delineated decadal rainfall zones in Eastern Africa region. Advances in Water Resources, 54, 161-180. doi:10.1016/j.advwatres.2013.01.001.

Omondi, P., Awange, J., Ogallo, L., Okoola, R., \& Forootan, E. (2012). Decadal rainfall variability modes in observed rainfall records over East Africa and their relations to historical sea surface temperature changes. Journal of Hydrology, 464-465, 140-156. doi:10.1016/j.jhydrol.2012.07.003.

Omondi, P. A., Awange, J. L., Forootan, E., Ogallo, L. A., Barakiza, R., Girmaw, G. B., Fesseha, I., Kululetera, V., Kilembe, C., Mbati, M. M., Kilavi, M., King'uyu, S. M., Omeny, P. A., Njogu, A., Badr, E. M., Musa, T. A., Muchiri, P., Bamanya, D., \& Komutunga, E. (2014). Changes in temperature and precipitation extremes over the greater horn of africa region from 1961 to 2010. International Journal of Climatology, 34, 1262-1277. doi:10.1002/joc. 3763 .

Preisendorfer, R. (1988). Principal component analysis in meteorology and oceanography. Elsevier.

Reager, J. T., \& Famiglietti, J. S. (2009). Global terrestrial water storage capacity and flood potential using grace. Geophysical Research Letters, 36, n/a-n/a. URL: http://dx.doi.org/10.1029/2009GL040826. doi:10.1029/ 2009 GL040826. 
Rientjes, T. H. M., Haile, A. T., Kebede, E., Mannaerts, C. M. M., Habib, E., \& Steenhuis, T. S. (2011). Changes in land cover, rainfall and stream flow in Upper Gilgel Abbay catchment, Blue Nile basin - Ethiopia. Hydrology and Earth System Sciences, 15, 1979-1989. doi:10.5194/hess-15-1979-2011.

Rodell, M., Chen, J., Kato, H., Famiglietti, J. S., Nigro, J., \& Wilson, C. R. (2007). Estimating groundwater storage changes in the Mississippi River basin (USA) using GRACE. Hydrogeology Journal, 15, 159-166. doi:10 . $1007 / \mathrm{s} 10040-006-0103-7$.

Rodell, M., \& Famiglietti, J. S. (2001). An analysis of terrestrial water storage variations in illinois with implications for the gravity recovery and climate experiment (grace). Water Resources Research, 37, 1327-1339. doi:10.1029/ $2000 W R 900306$.

Rodell, M., Houser, P. R., Jambor, U., Gottschalck, J., Mitchell, K., Meng, C.-J., Arsenault, K., Cosgrove, B., Radakovich, J., Bosilovich, M., \& et al. (2004). The Global Land Data Assimilation System. Bulletin of the American Meteorological Society, 85, 381-394. doi:10.1175/BAMS-85-3-381.

Rodell, M., Velicogna, I., \& Famiglietti, J. S. (2009). Satellite-based estimates of groundwater depletion in India. Nature, 460, 999-1002. doi:10.1038/ nature08238.

Romilly, T. G., \& Gebremichael, M. (2011). Evaluation of satellite rainfall estimates over ethiopian river basins. Hydrology and Earth System Sciences, 15, 1505-1514. doi:10.5194/hess-15-1505-2011.

Sawicz, K., Wagener, T., Sivapalan, M., Troch, P. A., \& Carrillo, G. (2011). Catchment classification: empirical analysis of hydrologic similarity based on catchment function in the eastern USA. Hydrology and Earth System Sciences, 15, 2895-2911. doi:10.5194/hess-15-2895-2011.

Schmidt, R., Flechtner, F., Meyer, U., Neumayer, K.-H., Dahle, C., König, R., 
\& Kusche, J. (2008). Hydrological signals observed by the GRACE satellites. Surveys in Geophysics, 29, 319-334. doi:10.1007/s10712-008-9033-3.

Segeke, Z., Lamb, P. J., \& Leslie, L. M. (2009). Seasonal-to-interannual variability of Ethiopia/Horn of Africa monsoon. Part I: Associations of waveletfiltered large-scale atmospheric circulation and global sea surface temperature. Journal of Climate, 22, 3396-3421. doi:10.1175/2008JCLI2859.1.

Seleshi, Y., \& Camberlin, P. (2006). Recent changes in dry spell and extreme rainfall events in Ethiopia. Theoretical and Applied Climatology, 83, 181-191. URL: 10.1007/s00704-005-0134-3. doi:10.1007/s00704-005-0134-3.

Seleshi, Y., \& Zanke, U. (2004). Recent changes in rainfall and rainy days in Ethiopia. International Journal of Climatology, 24, 973-983. doi:10.1002/ joc. 1052 .

Senay, G. B., Asante, K., \& Artan, G. (2009). Water balance dynamics in the Nile Basin. Hydrological Processes, 23, 3675-3681. doi:10.1002/hyp.7364.

Shang, H., Yan, J., Gebremichael, M., \& Ayalew, S. M. (2011). Trend analysis of extreme precipitation in the Northwestern Highlands of Ethiopia with a case study of Debre Markos. Hydrology and Earth System Sciences, 15, 1937-1944. doi:10.5194/hess-15-1937-2011.

Siebert, S., Henrich, V., Frenken, K., \& Burke, J. (2013). Update of the Digital Global Map of Irrigation Areas (GMIA) to Version 5. Documentation Institute of Crop Science and Resource Conservation Rheinische FriedrichWilhelmsUniversität Bonn and FAO Bonn, Germany and Rome, Italy.

Sutcliffe, J., \& Parks, Y. (1999). The Hydrology of the Nile. Technical Report International Association of Hydrological Sciences Oxfordshire, UK. Special Publication No.5.

Swenson, S., Famiglietti, J., Basara, J., \& Wahr, J. (2008). Estimating profile soil moisture and groundwater variations using GRACE and Okla- 
homa Mesonet soil moisture data. Water Resources Research, 44,n/a-n/a. doi:10.1029/2007WR006057.

Swenson, S., \& Wahr, J. (2006). Post-processing removal of correlated errors in GRACE data. Geophysical Research Letters, 33, L08402. doi:10.1029/ 2005 GL025285.

Syed, T. H., Famiglietti, J. S., Rodell, M., Chen, J., \& Wilson, C. R. (2008). Analysis of terrestrial water storage changes from GRACE and GLDAS. $W a-$ ter Resources Research, 44, n/a-n/a. doi:10.1029/2006WR005779.

Tapley, B. D., Bettadpur, S., Ries, J. C., Thompson, P. F., \& Watkins, M. M. (2004). GRACE measurements of mass variability in the Earth System. Science, 305, 503-505. doi:10.1126/science.1099192.

Taye, M. T., \& Willems, P. (2012). Temporal variability of hydroclimatic extremes in the blue nile basin. Water Resources Research, 48, n/a-n/a. doi:10.1029/2011WR011466.

Tesfagiorgis, K., Gebreyohannes, T., Smedt, F., Moeyersons, J., Hagos, M., Nyssen, J., \& Deckers, J. (2011). Evaluation of groundwater resources in the Geba Basin, Ethiopia. Bulletin of Engineering Geology and the Environment, 70, 461-466. doi:10.1007/s10064-010-0338-3.

Wahr, J., Molenaar, M., \& Bryan, F. (1998). Time variability of the Earth's gravity field: Hydrological and oceanic effects and their possible detection using GRACE. Journal of Geophysical Research: Solid Earth, 103, 3020530229. doi:10.1029/98JB02844.

Werth, S., Güntner, A., Schmidt, R., \& Kusche, J. (2009). Evaluation of GRACE filter tools from a hydrological perspective. Geophysical Journal International, 179, 1499-1515. doi:10.1111/j.1365-246X.2009.04355.x.

Yadav, M., Wagener, T., \& Gupta, H. (2007). Regionalization of constraints on expected watershed response behavior for improved predictions in ungauged 
basins. Advances in Water Resources, 30, 1756-1774. doi:http://dx.doi. org/10.1016/j.advwatres.2007.01.005.

Yirdaw, S., Snelgrove, K., \& Agboma, C. (2008). GRACE satellite observations of terrestrial moisture changes for drought characterization in the Canadian prairie. Journal of Hydrology, 356, 84-92. doi:10.1016/j.jhydrol.2008. 04.004.

Yitbarek, A., Razack, M., Ayenew, T., Zemedagegnehu, E., \& Azagegn, T. (2012). Hydrogeological and hydrochemical framework of Upper Awash River basin, Ethiopia: With special emphasis on inter-basins groundwater transfer between Blue Nile and Awash Rivers. Journal of African Earth Sciences, 65, 46-60. doi:10.1016/j . jafrearsci.2012.01.002. 